Aus der Klinik für Nephrologie und Rheumatologie

(Prof. Dr. med. G. A. Müller)

im Zentrum Innere Medizin

der Medizinischen Fakultät der Universität Göttingen

\title{
Effekte von Angiopoetin-2 auf endotheliale Vorläuferzellen beim akuten ischämischen Nierenversagen der Maus
}

\author{
INAUGURAL - DISSERTATION \\ zur Erlangung des Doktorgrades \\ für Zahnheilkunde \\ der Medizinischen Fakultät der \\ Georg - August - Universität zu Göttingen \\ vorgelegt von \\ Rico Backhaus \\ aus \\ Nordhausen
}

Göttingen 2013 
Dekan:

Prof. Dr. rer. nat. H. K. Kroemer

I. Berichterstatter: PD Dr. med. D. Patschan

II. Berichterstatter: PD Dr. med. M. Schroeter

Tag der mündlichen Prüfung: 28.05.2014 


\section{Inhaltsverzeichnis}

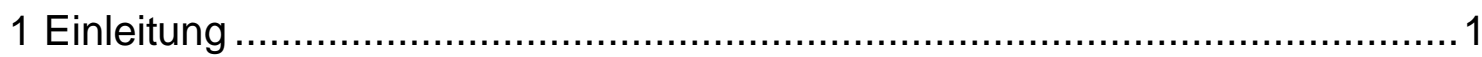

2 Stand der Forschung und Zielsetzung …........................................................

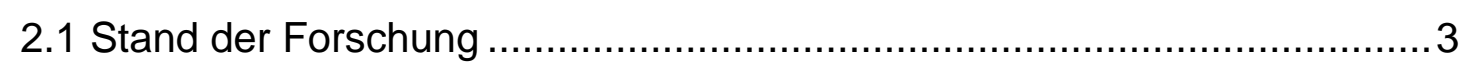

2.1.1 Das akute Nierenversagen ...........................................................

2.1.2 Endothel und Endothelvorläuferzellen ............................................. 4

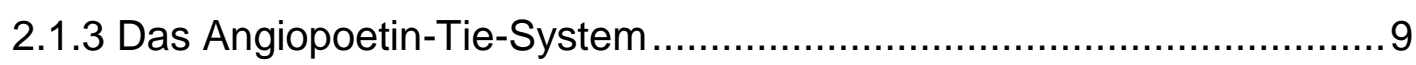

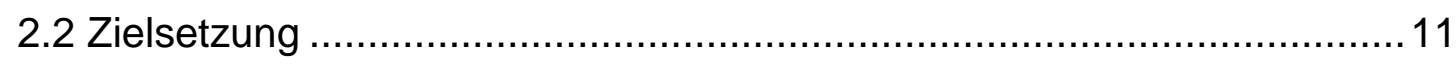

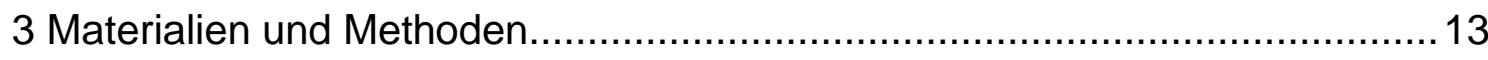

3.1 EPC-Gewinnung und Kultivierung aus Spendermäusen ..........................13

3.2 Markieren der Zellen vor Injektion mit 'Cell Tracker $\AA^{\circledR}$ ' ...........................14

3.3 Vorbehandlung der Zellen mit Angiopoetin-2 ........................................ 15

3.4 Operationstechnik und Operationsdurchführung .................................. 15

3.4.1 Allgemeines Operationsvorgehen ................................................. 15

3.4.2 Zellinjektion und Ischämiesimulation ..............................................16

3.4.3 Die Entnahme der Organe und des Blutes ..................................... 17

3.5 Erstellung von Gewebeschnitten für die mikroskopischen

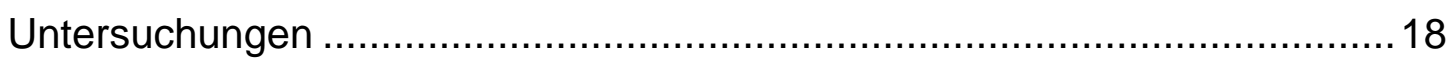

3.6 Dünnschnitte für die Immunfluoreszenzhistologie .................................22

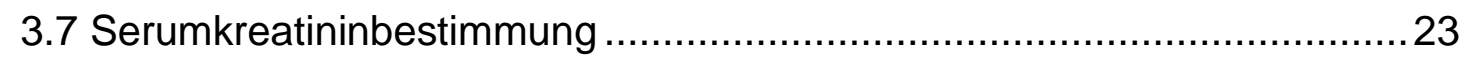

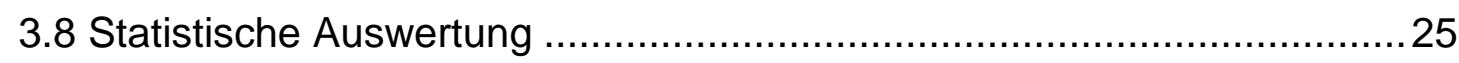

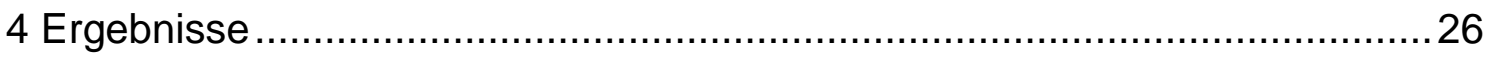

4.1 Darstellung der verschiedenen Versuchsgruppen .................................26

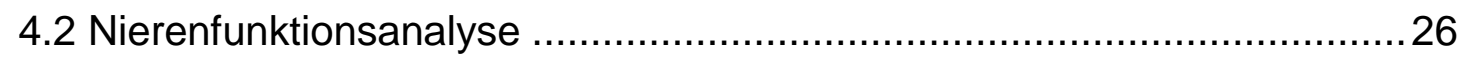

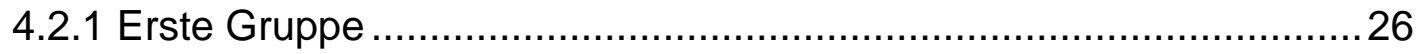

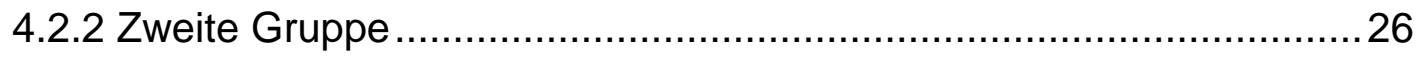

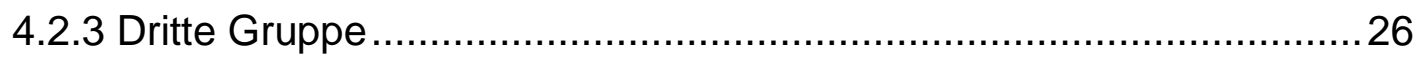

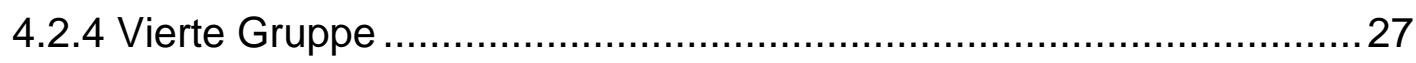


4.2.5 Fünfte Gruppe

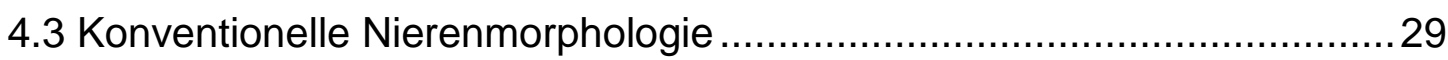

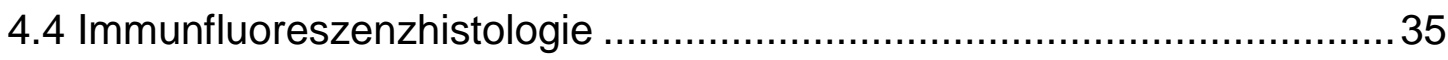

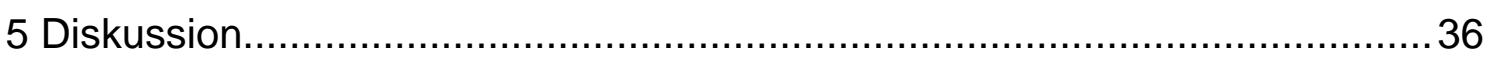

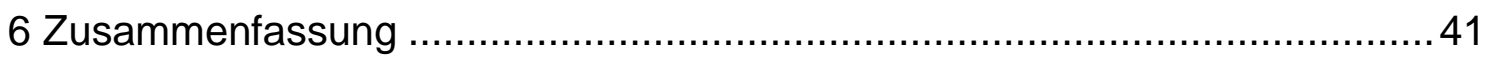

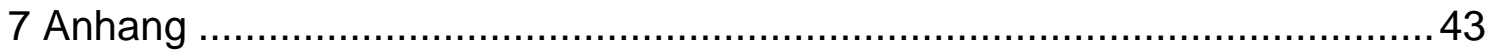

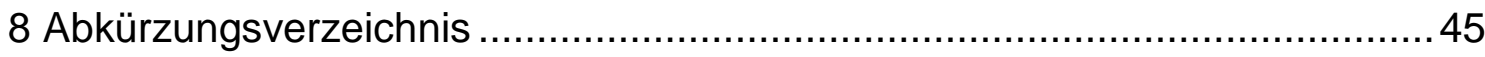

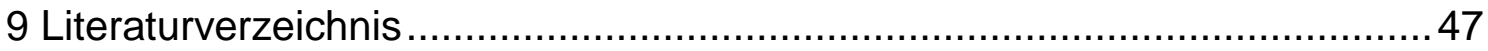




\section{Einleitung}

Die folgende Arbeit ist Teil eines Forschungsprojektes unter der Leitung von PD Dr. med. Daniel Patschan, welches sich mit der Etablierung von Endothelvorläuferzellen zum therapeutischen Einsatz bei akuten mikrovaskulären renalen Funktionsstörungen als Ursache des akuten Nierenversagens beschäftigt. Hierbei sollen Strategien und Kriterien etabliert werden, nach denen die exogene Gabe und/oder endogene Mobilisierung von Endothelvorläuferzellen zur Behandlung solcher akuten mikrovaskulären renalen Funktionsstörungen angewendet werden und unter welchen Bedingungen diese die größtmögliche nephroprotektive Wirkung entfalten können.

Das akute Nierenversagen (ANV) ist zu einem großen Anteil für die Morbidität und Mortalität stationär behandelter Patienten verantwortlich. Die Inzidenz des akuten Nierenversagens bei stationär behandelten Patienten liegt bei ungefähr $5 \%$. Bei intensivmedizinisch betreuten Patienten liegt sie sogar bei bis zu 30\% (Kribben et al. 2003; Lorenzen et al. 2010). Es tritt vor allem nach großen operativen Eingriffen sowie nach Multiorganversagen auf. Hierbei sind insbesondere der kardiogene Schock sowie die schwere Sepsis zu nennen (Lorenzen et al. 2010). Das akute Nierenversagen ist trotz des stetigen Fortschritts auf den Gebieten der Nierenersatztherapie (Dialyse) und Intensivmedizin die heutzutage kostenintensivste stationäre Nierenerkrankung. Angesichts der noch immer hohen Inzidenz wie auch Sterblichkeit ist die Identifizierung neuer therapeutischer Maßnahmen zur Behandlung des ANV unverändert ein wichtiges Ziel der experimentell-nephrologischen Forschung.

Endothelvorläuferzellen (Endothelial Progenitor Cells - EPCs) entwickeln sich zu einem wesentlichen Anteil aus pluripotenten hämatopoetischen Stammzellen im Knochenmark. Sie sind sowohl unter physiologischen als auch unter pathologischen Bedingungen permanent im Blut vorhanden und beteiligen sich an der Neubildung und Reparatur von kleinen Blutgefäßen (Asahara et al. 1997,1999; Khakoo und Finkel 2005; Urbich und Dimmeler 2004a+b). In den vergangenen Jahren wurden die Zellen wiederholt mit Erfolg aus unterschiedlichen Vertebratenorganismen isoliert und in der Behandlung ischämischer Erkrankungen eingesetzt. Im Rahmen der hier vorgelegten Arbeit wurde die therapeutische Injektion von Endothelvorläuferzellen beim akuten 
Nierenversagen im Mausmodell analysiert. Dabei wurde nach einer neuen Strategie gesucht, mit Hilfe derer das nephroprotektive Potential der Zellen beim ANV gesteigert werden kann. 


\section{Stand der Forschung und Zielsetzung}

\subsection{Stand der Forschung}

\subsubsection{Das akute Nierenversagen}

Bei einem akuten Nierenversagen kommt es zu einer plötzlichen Verschlechterung der Nierenfunktion, die durch einen Anstieg der Nierenretentionsparameter um wenigstens $50 \%$ des Ausgangswertes sowie, in den meisten Fällen (70\%), durch eine reduzierte Urinproduktion gekennzeichnet ist (Kribben et al. 2003). Hierbei kann sich der Zeitraum von wenigen Stunden bis einige Tage erstrecken. Das ANV ist grundsätzlich reversibel. Die große Bedeutung des ANV, nicht zuletzt auch aus ökonomischer Sicht, ergibt sich aus der Tatsache, dass die Erkrankung eine signifikante Erhöhung von Morbidität und Mortalität stationär behandelter Patienten zur Folge hat. Die Inzidenz des ANV liegt im Krankenhaus bei ungefähr $5 \%$, bei intensivmedizinisch betreuten Patienten steigt sie auf bis zu 30-50\% an (Kribben et al. 2003; Lorenzen et al. 2010). Ein ANV tritt vor allem nach großen operativen Eingriffen sowie im Rahmen eines Multiorganversagens auf, insbesondere der kardiogene Schock sowie die schwere Sepsis sind zu nennen (Lorenzen et al. 2010). Eine multinationale Studie beziffert die Sepsis mit ca. $50 \%$ als häufigste singuläre Ursache des nosokomialen ANV (Rifai et al. 2010). Die Mortalität des akuten Nierenversagens liegt in neueren Studien zwischen $28 \%$ und 90\% (Rifai et al. 2010; Bahte et al. 2010). Studien der National Hospital Discharge Survey der USA ergaben einen dortigen Anstieg der Inzidenz des ANV von 1980-2005 um das ca. 20-fache (Centers for Disease Control and Prevention 2008).

Eine, meist nur vorübergehende, generalisierte Minderperfusion der Nieren ist die häufigste Ursache des ANV (Kribben et al. 2003). Dabei spricht man vom akuten ischämischen Nierenversagen. Beim ischämischen ANV werden insbesondere die Tubulusepithelzellen in Mitleidenschaft gezogen bzw. die Zellen werden funktionell beeinträchtigt / strukturell geschädigt. Es gilt jedoch schon seit vielen Jahren als gesichert, dass gleichfalls strukturelle Veränderungen renaler Endothelzellen die Erholung der Niere nach einer Ischämie beeinflussen können (Goligorsky 2005). Bei einer Ischämie kommt es regelmäßig zur Schwellung der arteriolären / kapillären Endothelzellen. Dadurch 
wird die Reperfusion der Endstrombahn gehemmt (no-reflow phenomenon) (Leaf 1973). Als Folge dieser verminderten Durchblutung erholt sich die Nierenfunktion langsamer (Brodsky et al. 2002). Die Wiederherstellung der renalen Mikrozirkulation erstreckt sich über einen Zeitraum von circa 24 Stunden. Im Laufe dieses Prozesses zeigen sich oszillierende Verengungen und Erweiterungen der renalen Kapillaren (Yamamoto et al. 2002).

\subsubsection{Endothel und Endothelvorläuferzellen}

\subsubsection{Endothel}

Die Blutgefäße sind zur Innenseite durch das Endothel ausgekleidet. Dieses ist ein einschichtiges flaches Plattenepithel mesodermalen Ursprungs (Meyne 2003). Es ist in seiner Rolle für den Gesamtorganismus unentbehrlich. Aufgrund seiner bedeutenden Lage zwischen Blut und umliegenden Gewebe kommen dem Endothel zahlreiche Funktionen zu. Zum einen regelt es wesentlich den dort stattfindenden Stoffaustausch. Weiterhin ist es Bestandteil bei der Hemmung und Aktivierung der Blutgerinnung und es sezerniert eine Reihe vasoaktiver Substanzen, wie z.B. Stickstoffmonoxid. Im Rahmen von Entzündungsprozessen produziert das Endothel bestimmte Zytokine und Wachstumsfaktoren, die das Einwandern von antiinflammatorischen Zellen in das darunterliegende Gewebe fördern. Auch die Sprossung neuer Blutgefäße im Rahmen der Angiogenese erfolgt aus dem Endothel bzw. dessen einschichtigen, zusammenhängenden Zellen (Meyne 2003). Der Kontakt innerhalb der Endothelzellen kann hierbei in Dichtigkeit und Durchlässigkeit unterschiedlich sein. Der dichteste Kontakt des Endothelverbundes wird durch die sogenannten tight junctions hergestellt. Bei dieser Verbindung ist das Endothel kontinuierlich. Etwas durchlässiger zeigt sich das fenestrierte Endothel. Dieses ist mit den gleichen Zellkontakten wie das kontinuierliche Endothel ausgestattet, weist jedoch Ansammlungen von sogenannten Fenstern (ca. $70 \mathrm{~nm}$ ) auf. Jedes dieser Fenster ist mit einem Diaphragma versehen, durch das Wasser und kleine hydrophile Moleküle zügig durchtreten können. Diese Endothelform finden wir auch in den peritubulären Kapillaren der Niere. Die unter dem Endothel befindliche Basalmembram ist hier auch, wie beim kontinuierlichen Endothel, durchgehend. Die durchlässigste Art einer Endothelbeziehung ist das diskontinuierliche Endothel. Eine durchgängige 
Endothelschicht ist hier nicht mehr vorhanden, auch die darunterliegende Basallamina existiert nicht. Wir finden eine solche Art des Endothels beispielsweise in der Leber (Lüllmann-Rauch und Paulsen 2012).

\subsubsection{Endothelvorläuferzellen}

Die Ausbildung von Blutgefäßen findet nicht, wie früher angenommen, nur während der Embryonalphase statt, sondern vollzieht sich sowohl unter physiologischen als auch pathologischen Bedingungen während des gesamten postnatalen Lebens. Dies zeigt sich sowohl in der Zunahme der Gefäß- und Kapillardichte infolge körperlichen Trainings (physiologisch) als auch in der Gefäßdichtenzunahme bei malignem Gefäßwachstum (pathologisch). Der Prozess der Gefäßneubildung wird als Neovaskularisation bezeichnet. Hierbei unterscheidet man zweierlei Wege, den der Angiogenese (Khakoo und Finkel 2005; Urbich und Dimmeler 2004a+b) und den der Vaskulogenese (Patschan et al. 2006a; Bailey et al. 2004). Die Angiogenese ist dadurch gekennzeichnet, dass die lokale Proliferation ortsständiger, reifer Endothelzellen sowie anderer Gefäßwandzellen die Ausbildung neuer Arteriolen, Kapillaren und Venolen herbeiführt (Khakoo und Finkel 2005; Urbich und Dimmeler 2004a+b). Bei der Vaskulogenese differenzieren sich spezielle Progenitor- bzw. Stammzellen in reife Gefäßwandzellen. Lange Zeit wurde angenommen, dass der Prozess der Vaskulogenese ausschließlich im Rahmen der Embryonalentwicklung stattfindet. Es konnte aber inzwischen wissenschaftlich eindeutig belegt werden, dass dieser Prozess zeitlebens im gesamten adulten Vertebratenorganismus stattfindet. Für diesen Prozess sind endotheliale Vorläuferzellen, sogenannte EPCs (Endothelial Progenitor Cells), von fundamentaler Bedeutung.

Im Jahr 1997 wurden von Asahara et al. erstmals im Blut zirkulierende EPCs nachgewiesen (Asahara et al. 1997). In ihren Untersuchungen isolierten die Autoren CD34+-Leukozyten aus humanem Blut und kultivierten diese unter bestimmten Bedingungen. Nach einigen Tagen wurden die heranwachsenden Zellen untersucht. Sie wiesen sowohl morphologisch als auch bezüglich ihres Oberflächenmarkerprofils typische endotheliale Eigenschaften auf. Diese Zellen wurden nun in Versuchstiere, die an Extremitätenischämien litten, injiziert. Zellbehandelte Tiere wiesen eine deutlich schnellere Erholung des postischämischen Gewebes auf. Zudem konnten die Zellen mikroskopisch in den 
Kapillarwänden nachgewiesen werden. Diese Ergebnisse waren wegweisend für die kommenden Untersuchungen und Versuche von und mit EPCs.

Die Wissenschaft konnte seitdem EPCs sehr viel genauer charakterisieren. Es deutet sich zunehmend an, dass es zwei Hauptpopulationen endothelialer Progenitorzellen gibt. Die eine Population wird von Zellen repräsentiert, die sich mehrheitlich aus pluripotenten hämatopoetischen Stammzellen im Knochenmark entwickeln (Bailey et al. 2004; Grant et al. 2002). Diese Gruppe ist die bisher am genausten untersuchte. Diese - als early Endothelial Outgrowth Cells (eEOCs) bezeichneten - exprimieren zum einen verschiedene 'unreife' Zellmarker [c-Kit, CD34, CD 133, (Rafii und Lyden 2003)], zum anderen gleichfalls verschiedene endotheliale Zellmarker wie KDR und Flk-1 [humaner bzw. muriner Typ-2-Rezeptor für VEGF (Khakoo und Finkel 2005)], Tie-2 [Rezeptor für Angiopoetin-1 (Wakui et al. 2006)] und CD31 [PECAM-1, endotheliales Zelladhäsionsmolekül (Baldwin et al. 1994)]. In Kultur können diese Zelltypen in EBM-2-Medium auf Fibronektin-beschichteten Platten nach circa 5-7 Tagen heranwachsen. In zahlreichen Tiermodellen zeigten sich für eEOCs Ischämie-protektive Wirkungen. So konnten eEOCs etwa im Randbereich von infarziertem Myokard ('Grenzzone') nachgewiesen werden, nachdem sie systemisch bei knochenmarkstransplantierten Tieren mit iatrogenem Herzinfarkt systemisch appliziert wurden. Die Mehrzahl der Zellen stammte vom Spenderorganismus ab (Asahara et al. 1999; Schuster et al. 2004). In klinischen Untersuchungen konnte zudem gezeigt werden, dass bei Patienten mit koronarer Herzkrankheit die Anzahl peripher zirkulierender eEOCs im Blut vermindert ist (Adams et al. 2004; Lambiase et al. 2004).

Bei der anderen Unterpopulation ist davon auszugehen, dass es sich hier um 'echte' Endothelvorläuferzellen handelt, da sie phänotypisch den reifen Endothelzellen sehr ähneln und nach systemischer Injektion in ausgeprägterem Maße in die Wände der kleinen Blutgefäße inkorporieren. In der ersten Beschreibung von Lin et al. wurden sie als late Endothelial Outgrowth Cells (IEOCs) definiert (Lin et al. 2000). Im Vergleich zu den 'klassischen' EPCs müssen IEOCs auf Kollagen über einen Zeitraum von ca. 3 Wochen kultiviert werden. Zudem haben sie eine sehr viel ausgeprägtere proliferative Kapazität als reife Endothelzellen. Im Gegensatz zu eEOCs zeigen sie eine deutlichere Vaskulogeneseaktivität (Case et al. 2007; Yoder et al. 2007). Im Rahmen der 
hier vorgestellten Untersuchungen wurde mit eEOCs gearbeitet, daher sind im Folgenden mit dem Terminus EPCs stets eEOCs gemeint.

Rehman et al. (2003) konnten zeigen, dass die zellulären Mechanismen der EPC-vermittelten Vasoprotektion nicht nur auf eine direkte vasale Inkorporation und die weitere endotheliale Differenzierung der Zellen beschränkt ist. Die Zellen sind auch in der Lage, proangiogene Wachstumsfaktoren (VEGF, HGF, G-CSF, GM-CSF) zu sezernieren (Rehman et al. 2003). Damit können sie vermutlich eine Rückbildung von potentiell reversiblen Endothelveränderungen vermitteln, wie z.B. die ischämieassoziierte Zellschwellung mit Einengung des Gefäßlumens (Urbich und Dimmeler 2004a).

Die Bedeutung von EPCs konnte bisher vor allem für die koronare Herzkrankheit belegt werden. Die pathophysiologische Bedeutung von EPCs bei renalen Erkrankungen ist hingegen weniger genau erforscht. Es konnte bisher eine Beteiligung der Zellen an der Regeneration des glomerulären Endothels im Rahmen der (experimentellen) anti-Thy 1.1 Glomerulonephritis nachgewiesen werden (Rookmaker et al. 2003). Zudem hat sich gezeigt, dass Patienten mit chronischer Niereninsuffizienz eine verminderte Anzahl von EPCs im Blut aufweisen (de Groot et al. 2004). Dieses Phänomen ist ähnlich dem der Patienten, die an einer koronaren Herzkrankheit leiden. In Bezug auf die Bedeutung endothelialer Vorläuferzellen bei akuten mikrovaskulären Dysfunktionen der Niere gab es bislang nur wenige Erkenntnisse. Die ersten Ergebnisse lieferte die Arbeitsgruppe von Prof. Goligorsky (Yamamoto et al. 2002). In diesen Untersuchungen wurden immuninkompetenten Ratten ('nude rats') mit beidseitiger renaler Ischämie so genannte 'human umbilical vein endothelial cells' (HUVECs - ausgereifte humane Endothelzellen) systemisch injiziert. Die Nierenfunktion der behandelten Tiere verbesserte sich signifikant im Vergleich zu derjenigen der Kontrollgruppen. Histologische Untersuchungen zeigten, dass die injizierten Zellen sowohl in den tubulären als auch in den glomerulären Kapillarwänden nachweisbar waren. Diese Tatsache verdeutlichte, dass die infundierten Zellen die strukturelle und funktionelle Erholung der Kapillaren beschleunigen und somit die schnellere Wiederherstellung der Nierenfunktion begünstigen. 


\subsubsection{Endothelvorläuferzellen bei renaler Ischämie}

Anfang 2006 konnte Herr PD Dr. med D. Patschan die prinzipielle therapeutische Anwendbarkeit von Endothelvorläuferzellen zur Behandlung des akuten ischämischen Nierenversagens erstmalig zeigen (Patschan et al. 2006b). Die vorgestellten Ergebnisse belegten, dass eine akute renale Ischämie Endothelvorläuferzellen mobilisiert. Dies geschieht innerhalb von 3-6 Stunden nach Reperfusion. Weiterhin wurde gezeigt, dass eine ischämische Präkonditionierung zur Translokation von mobilisierten EPCs in die postischämische Niere führt. Diese EPC-Infiltrate sind im medullären Anteil der geschädigten Niere signifikant ausgeprägter. Dr. Patschan konnte in weiteren Experimenten belegen, dass EPCs gleichfalls durch die beiden Substanzen Harnsäure und TNF- $\alpha$ (Tumor-Nekrosefaktor-alpha) mobilisiert werden. Hierbei war in FVB/NJ-Mäusen der EPC-mobilisierende Effekt von Harnsäure nur unter

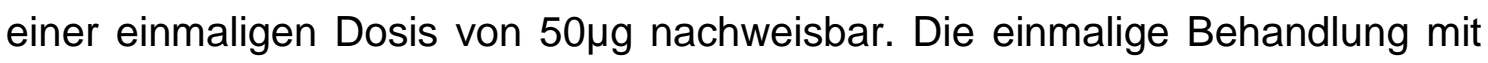
den Harnsäure-Präkursoren Adenosin und Inosin führte hingegen nicht zu einer Mobilisierung der Zellen. Nach 30-minütiger, beidseitiger renaler Ischämie stieg die systemische Harnsäurekonzentration auf denselben Wert an wie nach einer

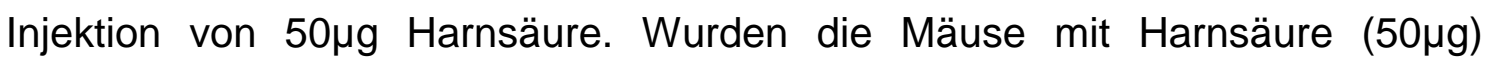
einmalig vorbehandelt, resultierte eine nephroprotektive EPC-Mobilisierung. Die mobilisierten EPCs waren hier im postischämischen Organ nachweisbar. Die Vorbehandlung von Harnsäure in Kombination mit Urikase führte nicht zur EPCMobilisierung (Patschan et al. 2007). Im Jahr 2009 konnte zudem eine erste Strategie erarbeitet werden, mit Hilfe derer sich die nephroprotektive Wirkung der EPCs signifikant verstärken ließ. Die in-vitro-Vorbehandlung mit dem Integrinrezeptoraktivator 8-O-cAMP induzierte ein verstärktes homing syngener muriner EPCs in die Nieren postischämischer Mäuse. Die kurzfristige Vorbehandlung mit 8-O-cAMP führte hierbei nicht zu einer quantitativ vermehrten Expression von $\beta 1$-Intergrinen in den Zellen, es zeigte sich jedoch eine Umverteilung der Adhäsionsmoleküle auf die Oberfläche der EPCs. Dadurch wurde die reparative Wirkung am Ort der Minderdurchblutung verstärkt (Patschan et al. 2010). Letzte Untersuchungen wurden auf die Vorbehandlung der EPCs mit Melatonin durchgeführt (Patschan et al. 2012). Hier konnte gezeigt werden, dass Melatonin die nephroprotektiven Effekte endothelialer Progenitorzellen im akuten Nierenversagen verstärkt. In den Versuchen wurden 
nach einer 40-minütigen renalen Ischämie bei Mäusen EPCs mit einer 1stündigen Melatoninvorbehandlung injiziert. Die nephroprotektiven Eigenschaften jener Zellen waren signifikant besser als die der Zellen ohne Melatoninbehandlung. Bei gleichzeitiger Vorbehandlung der Zellen mit Melatonin und dem MT-1/-2-Antagonisten Luzindol waren keine verbesserten nephroprotektiven Eigenschaften festzustellen. In-vitro-Studien zeigten, dass sich durch die Melatoninbehandlung die TNF- $\beta$ induzierte EPC-Nekrose bzw. Apoptose merklich reduzieren ließ. Die VEGF-Sekretion der EPCs konnte durch die Melatoninvorbehandlung gleichfalls gesteigert werden. Mit diesen Ergebnissen wurde Melatonin gleichfalls als neuer Agonist von EPCs identifiziert.

\subsubsection{Das Angiopoetin-Tie-System}

Das Angiopoetin-Tie-System besteht aus den zwei Rezeptor-Tyrosin-Kinasen Tie-1 und Tie-2 sowie den 4 Liganden Angiopoetin 1-4 (Gale und Yancopoulos 1999). Die Tie-Rezeptoren befinden sich in der Plasmamembran. Es sind ausschließlich Endothelzellen, endotheliale Vorläuferzellen und hämatopoetische Stammzellen in der Lage, sie zu exprimieren (Dumont et al. 1992; Partanen et al. 1992; Iwama et al. 1993; Sato et al. 1993; Schnürch und Risau 1993; Korhonen et al. 1994).

Beide Rezeptoren sind sich strukturell ähnlich (Schnürch und Risau 1993). Untersuchungen konnten die Wichtigkeit von Tie-1 und Tie-2 für die sprossende Angiogenese und deren Notwendigkeit für die spätere Erhaltung der vaskulären Integrität zeigen (Dumont et al. 1994; Sato et al. 1995).

Die am genauesten untersuchten Liganden des Tie-2-Rezeptors sind Ang-1 und Ang-2. Für den Tie-1-Rezeptor konnte bislang kein direkter Ligand identifiziert werden. Angiopoetin-1 besitzt jedoch die Fähigkeit, unter Vermittlung von Integrinen an Tie-1 zu binden (Saharinen et al. 2005; Carlson et al. 2001). Ang-1 und Ang-2 sind Glykoproteine mit einem Molekulargewicht von circa $70 \mathrm{kDa}$ (Maisonpierre et al. 1997). Angiopoetin-2 liegt überwiegend als Dimer, Angiopoetin-1 hingegen als Tetramer vor. Beide sind prinzipiell in der Lage, verschiedene Multimere auszubilden (Davis et al. 2003; Kim et al. 2005). Sie binden mit vergleichbarer Affinität an die Tie-2-Bindungsstelle (Fiedler et al. 2003; Maisonpierre et al. 1997), wobei Ang-1 hier zur Phosphorylierung des 
Rezeptors führt (Davis et al. 1996; Davis et al. 2003) und Ang-2 nicht (Maisonpierre et al. 1997). Ang-1 wird wesentlich von glatten Muskelzellen, Perizyten, Fibroblasten und teilweise auch von einigen Tumoren gebildet (Davis et al. 1996; Stratmann et al. 1998; Sugimachi et al. 2003). Im Vergleich dazu wird Ang-2 hauptsächlich von Endothelzellen produziert und freigesetzt (Hegen et al. 2004). Die Expression von Ang-2 wird genau reguliert. Physiologisch wird es nur in geringen Mengen produziert. In hypoxischen Geweben oder nach Stimulation mit angiogenen Zytokinen wie VEGF kann eine erhöhte Freisetzung festgestellt werden (Oh et al. 1999). Kürzlich konnte die regulative Wirkung von Ang-2 auf die Responsivität des Endothels gegenüber angiogenen und inflammatorischen Zytokinen gezeigt werden. Sowohl VEGF, Bradikinin als auch Histamin steigern die Gefäßpermeabilität nur durch die Anwesenheit von Ang-2 (Kruse 2009).

Die Sekretion von Ang-2 aus endothelialen WPBs (Weibel - Palade bodies) geschieht zügig (Fiedler et al. 2004). In der Bindung an Tie-2 konkurriert Ang-2 mit Ang-1. Abhängig vom biologischen Kontext führt Ang-2 zu einer Reihe verschiedener Wirkungen. Es ist zum einen bei proinflammatorischen Aktionen durch eine Erhöhung der Gefäßpermeabilität beteiligt, zum anderen ist Ang-2 aber auch für die zellschützende Funktion von EPCs essentiell (Maisonpierre et al. 1997; Roviezzo et al. 2005; Lemieux et al. 2005). Somit ist eine genaue Balance zwischen Ang-1- und Ang-2-Wirkung notwendig, damit inflammatorische Prozesse sowie mobilisierende Wirkungen auf EPCs bzw. HPCs entfaltet werden können. Es ist vorstellbar, dass eine große Gewebsverletzung und/oder hohe Harnsäurekonzentration die Wirkung des Ang-2 eher in Richtung „Proinflammation“ verschiebt. Verstärkt wird diese Vermutung durch die Ang-2induzierte Permeablitätserhöhung pulmonaler Blutgefäße nach Sepsis (Parikh et al. 2006). Die Ang-2-bedingte Mobilisierung von EPCs aus dem Knochenmark sowie ein fördernder Effekt auf die Migration ins Gewebe wird ebenfalls angenommen (Udani et al. 2005; Gill und Brindle 2005).

Das Angiopoetin/Tie-2-System stellt somit einen wichtigen Bestandteil der Regulation der Blutgefäßreifung bzw. -umgestaltung/Homöostase dar. Hierbei ist die Stabilität des bestehenden Gefäßsystems sowie dessen Neubildung und Umgestaltung von einer sehr genau ausbalancierten Wechselwirkung der Aktivierung des Tie-2-Rezeptors durch seine Liganden Ang-1 und Ang-2 
abhängig. Die ständige Sekretion von Ang-1 aus den perivaskulären Zellen aktiviert die Tie-2 Signalwege und hält somit die Integrität des Gefäßbetts aufrecht. Ang-2 wird hingegen nur nach Aktivierung der Endothelzellen exprimiert. Es liegt gespeichert in deren Weibel-Palade-Körperchen vor und wird nach Aktivierung sezerniert. Bei dieser Ausschüttung, aber auch bei Überexpression von Ang-2, wird das Gefäßbett aktiviert und in einen Zustand versetzt, in dem es auf angiogene und inflammatorische Zytokine reagieren kann. Diese Mechanismen zeigen, dass ein gut balanciertes Verhältnis von Ang-1 und Ang-2 und deren Verfügbarkeit unabdingbar sind, um die Integrität des Gefäßbetts aufrechtzuerhalten. Es wird vermutet, dass Ang-2 unter bestimmten Bedingungen mit Ang-1 agonistisch wirkt, obwohl es prinzipiell dessen Aktivierung von Tie-2 inhibiert. Ang-2 wirkt zudem positiv auf die Entwicklung von Lymphgefäßen und aktiviert die Sprossung von Endothelzellen (Ulrike Fiedler, Cesar Symposium 14. - 16. Juni 2007, Freiburg).

\subsection{Zielsetzung}

Das laufende Projekt der Arbeitsgruppe um PD Dr. med Daniel Patschan beschäftigt sich mit der Identifizierung weiterer, potentiell EPC-agonistischer Substanzen beim akuten ischämischen Nierenversagen der Maus. Neuere Resultate ergaben einen EPC-mobilisierenden Effekt für Angiopoetin-2 (Kuo et al. 2008).

Kuo et al. machten in ihren Versuchen folgende Feststellungen. Sie stellten einen Anstieg der Harnsäurekonzenration nach renaler Ischämie fest. Der Harnsäurekonzentrationsanstieg fungierte dabei als endogenes Alarmsignal. Exogen zugeführte Harnsäure mobilisiert EPCs und schützt die Niere vor einer ischämischen Schädigung. Die schnelle Wirkung der Harnsäure ließ hier auf eine second messenger - Kaskade schließen. MSU (monosodium urate) führte zur Exozytose der Weibel-Palade-Körperchen. Dabei wurden u.a. IL-8, vWF und Ang-2 freigesetzt. Ang-2 induzierte in dieser Situation eine Zunahme der WPB-Degranulation mit nachfolgender Mobilisierung endogener hämatopoetischer Stammzellen (HPCs), zudem reduzierte dies die Anzahl von in der Milz befindlichen EPCs. Weiterhin konnte Ang-2 die Wirkungen von MSU teilweise reproduzieren. Harnsäure triggert die Exozytose der WPBs sowohl in vivo als auch in vitro. Ang-2 schützt durch die oben genannte HPC- und EPC- 
Mobilisierung die Nierenfunktion nach Ischämie. In Versuchen wurde dabei ein rapider Anstieg von HSCs (CD150+/c-Kit+cells) im Blut sowie in der Milz festgestellt, wohingegen die Anzahl der EPCs in der Milz sank.

Die in vitro-Effekte von Ang-2 auf EPCs beim ischämischen ANV sind jedoch noch vollständig unbekannt.

Eine mögliche Erhöhung des antiischämischen Potentials von EPCs durch die Vorbehandlung mit Angiopoetin-2 sollte mit Hilfe dieser Arbeit untersucht werden. 


\section{Materialien und Methoden}

\subsection{EPC-Gewinnung und Kultivierung aus Spendermäusen}

Die EPCs, die im Rahmen der vorliegenden Arbeit verwendet wurden, sind vor eigentlicher Versuchsdurchführung zuvor aus syngenen männlichen 8-12 Wochen alten C57BI/6N-Mäusen (Jackson Laboratory, Bar Harbor, USA) zunächst isoliert und anschließend kultiviert worden. Die Zellisolation erfolgte stets unter sterilen Bedingungen aus dem Vollblut und den Milzen der Mäuse. Vor Entnahme wurden die Spendermäuse zunächst anästhesiert. Als Anästhetikum wurde ein Gemisch aus Ketamin und Xylazin verwendet. Das Ketamin dient hierbei als Narkotikum mit analgetischer Wirkung und das Xylazin als zusätzlich verstärkendes Analgetikum. Zur Herstellung dieses geeigneten Anästhetikums wurden $520 \mu \mathrm{l}$ einer vorgefertigten Lösung (Firma SIGMAALDRICH, Katalog Nr.:K-113) mit 6,8 ml destilliertem Wasser gemischt. Das destillierte Wasser wurde zuvor unter sterilen Bedingungen selbst hergestellt. Die vorgefertigte Lösung der Firma enthielt bereits die Stoffe Ketamin und Xylazin (10 ml enthalten $800 \mathrm{mg}$ Ketamine HCL und $120 \mathrm{mg}$ Xylazine HCL). Vor der durchzuführenden OP wurden jeder Maus ca. 300-400 $\mu \mathrm{l}$ des Anästhetikums injiziert. Bei Bedarf musste natürlich nachinjiziert werden. Die sichere Anästhesietiefe wurde mit einer "Wachheitsprobe“ überprüft. Hierzu wurde mit Hilfe einer Pinzette die Schwanzspitze kurz zusammengedrückt. Konnte während dieser Probe keine Regung der Maus festgestellt werden, war eine ausreichende Anästhesietiefe anzunehmen. Nun wurde der Bauchraum eröffnet und mit einer Spritze transdiaphragmal so viel Blut wie möglich aus dem schlagenden Herzen entnommen und samt der Spritze auf Eis gelegt werden. Die Spritze wurde zuvor mit einem Tropfen Heparin (Heparin-Natrium 25000, Firma RATIOPHARM, Katalog Nr.: N21086.21-Z04) gefüllt, um ein Gerinnen des Blutes zu verhindern. Nach Blutentnahme wurde die Milz derselben Maus entnommen und in ein $15 \mathrm{ml}$ - Greiner Röhrchen® überführt. Nach Zerstampfen der Milz zwecks Homogenisierung mit Hilfe eines Tuberkulinspritzenkolbens wurde das Greiner- Röhrchen $\AA^{\circledR}$ ebenfalls auf Eis gelegt. Nun wurden das Vollblut und die Milzhomogenisatüberstände in $4 \mathrm{ml}$ Histopaque-Lösung eines $50 \mathrm{ml}$ Greiner- Röhrchens ${ }^{\circledR}$ überführt. Anschließend erfolgte eine Zentrifugation bei $4^{\circ} \mathrm{C}$ mit $1400 \mathrm{U} / \mathrm{min}$ für $30 \mathrm{~min}$ "ohne Bremse“ 
(Zentrifuge der Firma Beckmann Typ: G5-6R). Im Anschluss daran wurde die mononukleäre Zellfraktion (MNC) mit einer $1 \mathrm{ml}$ Pipette abgenommen und in ein $50 \mathrm{ml}$ Gefäß überführt sowie anschließend mit EBM-2-Medium auf $40 \mathrm{ml}$ aufgefüllt. Danach erfolgte eine erneute Zentrifugation, diesmal für 10 Minuten bei $1400 \mathrm{U} / \mathrm{min}$ "mit Bremse“. Es folgte eine erneute Abnahme der MNCs und deren Resuspension in $2 \mathrm{ml}$ EBM-Medium. Die Zellen konnten nun in einer Neubauerkammer gezählt und verdünnt werden, dass jeweils $2-4 \times 10^{6}$ EPCs in $2 \mathrm{ml}$ EBM-2 gelöst waren. Je $2 \mathrm{ml}$ dieser Lösung wurden nun in je eine Vertiefung einer fibronektinbeschichteten 6-Well-Kulturplatte pipettiert werden (Fibronektin der Firma SIGMA-ALDRICH, F0895 - IMG). Nach 4 Tagen konnten die nichtadhärenten Zellen verworfen werden und es folgte ein Mediumwechsel in frisches EBM-2-Medium für 3 weitere Tage. Danach waren die Zellen für die Markierung mit 'Cell Tracker®' (Firma INVIT-ROGEN, Katalog Nr.: C700) vor Injektion vorbereitet.

\subsection{Markieren der Zellen vor Injektion mit 'Cell Tracker®'}

Die Markierung der Zellen dient dazu, die nach systemischer Injektion von kultivierten EPCs in der postischämischen Niere eingewanderten Zellen beurteilen zu können. Zunächst wurde das Medium abgesaugt und jeweils 0,2 $\mathrm{ml}$ Trypsin-Lösung zugegeben. Diese wurde für etwa 5 Minuten bei $37^{\circ} \mathrm{C}$ auf den Zellen belassen. Im Anschluss wurden die Zellen mit 0,5 ml EBM-2 von der Kulturplattenfläche gewaschen. Hierzu wurde eine Pipette verwendet. Das entstandene Gemisch wurde nun in ein $50 \mathrm{ml}$ Greiner-Röhrchen $\AA$ gegeben und für $10 \mathrm{~min}$ bei erneut $1400 \mathrm{U} / \mathrm{min}$ zentrifugiert. Zeitgleich konnten $50 \mu \mathrm{l}$ 'Cell Tracker ${ }^{\circledR}$ ' in $50 \mu \mathrm{l}$ reinem Ethanol gelöst werden. Die entstandene Lösung wurde mit EBM-2 im Verhältnis 1:1000 gemischt (z.B. $1 \mu$ lösung in $999 \mu \mathrm{l}$ EBM-2). Im nächsten Schritt wurden die Zellen in $1 \mathrm{ml}$ dieser Lösung resuspendiert und für 5 Minuten bei $37^{\circ} \mathrm{C}$ inkubiert um im Anschluss für 15 Minuten auf Eis gelegt zu werden. Danach fand eine erneute Zellauszählung in der Neubauerkammer statt. Mit EBM-2 wurde wieder auf $12 \mathrm{ml}$ aufgefüllt und bei $1400 \mathrm{U} / \mathrm{min}$ für 10 Minuten zentrifugiert. Abschließend wurden die Zellen so in EBM-2 resuspendiert, dass sich eine Konzentration von $0,5 \times 10^{6}$ Zellen je 50 $\mu \mathrm{l}$ ergab. Nun waren die Zellen markiert und für die systemische Injektion so vorbereitet, dass sie in die Injektionsspritzen aufgezogen werden konnten. 


\subsection{Vorbehandlung der Zellen mit Angiopoetin-2}

Vor der Markierung der Zellen mit oben benanntem 'Cell Tracker $\AA^{\circledR}$ ' wurde die eigentliche Zellvorbehandlung mit Angiopoetin-2 vorgenommen. Hierzu wurden die Zellen für je 1 Stunde in einem $50 \mathrm{ml}$ Falcon mit $50 \mu \mathrm{l}$ Stimulationslösung inkubiert. Die Konzentrationen des Ang-2 betrugen je nach Versuchsgruppe $400 \mathrm{ng} / \mathrm{ml}$ oder $800 \mathrm{ng} / \mathrm{ml}$. Das Ang-2 war bereits gebrauchsfertig (Recombinant Human Angiopoetin-2, Firma Biocat, Katalog Nr.: 4922-10). Nach erfolgter Inkubation wurde die Stimualtionslösung abzentrifugiert und die bereits beschriebene Markierung der Zellen mit 'Cell Tracker®' konnte erfolgen.

\subsection{Operationstechnik und Operationsdurchführung}

\subsubsection{Allgemeines Operationsvorgehen}

Als Grundlage dieser Arbeit dienten Tierexperimente mit männlichen Mäusen vom Typ C57BI/6N. Die Wahl des männlichen Geschlechts ergab sich aus der Tatsache, dass weibliche Tiere des Stammes häufiger eine gewisse "Ischämietoleranz" aufweisen. Vor Beginn der eigentlichen Versuche war die erfolgreiche Abnahme einer gewissenhaften und korrekten Operation dieser Tiere durch Herrn Prof. Dr. H. Jarry notwendig. Nach bestandener Prüfung erhielt der Operateur eine entsprechende 'Ausnahmegenehmigung' des Landes zur Durchführung dieses Eingriffes. Jedes Tier wurde einer zweitzeitigen Operation unterzogen. In der ersten Operation wurde dem Tier die Blutzufuhr der linken Niere mit Hilfe einer Gefäßklemme für 40 Minuten unterbunden. Während dieser 40 Minuten musste um den Gefäßstiel der rechten Niere eine Nahtligatur gelegt werden. Nach Ablauf der 40 Minuten, wurde die Gefäßklemme der linken Niere entfernt. Im sofortigen Anschluss

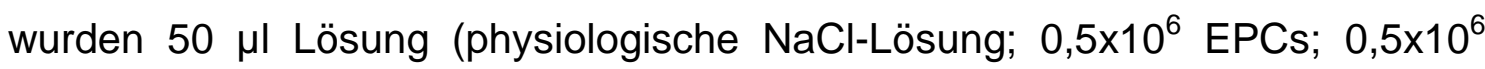
EPCs vorbehandelt mit $400 \mathrm{ng} / \mathrm{ml}$ Angiopoetin-2 sowie $0,5 \times 10^{6}$ EPCs vorbehandelt mit $800 \mathrm{ng} / \mathrm{ml}$ Angiopoetin-2) in die rechte Niere distal der gelegten Ligatur injiziert. Nach erfolgter Injektion wurde die Ligatur zugezogen und somit die komplette Blutzufuhr und -abfuhr zur rechten Niere unterbunden. Jetzt konnte die rechte Niere in toto entfernt werden. Somit konnte ein akutes ischämisches Nierenversagen induziert werden, da der jetzt stattfindende Nierenstoffwechsel nur noch über die abgeklemmte Niere möglich war. Die 
Durchführung der zweiten OP erfolgte 48 Stunden später. Hierbei wurden der Maus sowohl die in der ersten OP abgeklemmte Niere als auch möglichst viel Blut aus dem noch schlagenden Herzen entnommen.

\subsubsection{Zellinjektion und Ischämiesimulation}

Nach erfolgter Anästhesie wurde der Bauchraum der Maus mit Hilfe eines etwa $2 \mathrm{~cm}$ langen medianen Schnittes eröffnet. Die Bauchraumeröffnung erfolgte zweizeitig. Nach Desinfektion des einzuschneidenden Bereiches wurde zunächst die Hautschicht eingeschnitten, anschließend separat die Muskelschicht. Bei der Eröffnung des Bauchraumes musste eine Verletzung der inneren Organe vermieden werden. Um eine gute Sicht auf das OP-Gebiet zu erhalten, wurden die Gliedmaßen der Mäuse mit kleinen Pflasterstreifen an der Unterlage fixiert. Damit befand sich das jeweilige Tier in ruhiger Rückenlage und eine optimale Bauchraumeinsicht war gegeben.

Die Mobilisierung der inneren Organe erfolgte mit Hilfe mikrochirurgischer Instrumente und kleiner Wattestäbchen. Die Wattestäbchen und die Tücher wurden in steriler Kochsalzlösung getränkt, damit mögliche Verklebungen mit inneren Organen vermieden und somit keine Verletzungen herbeigeführt werden konnten. Zudem konnten so die Organe feucht gehalten werden.

Die Aufsuchung der linken Niere erfolgte mit Hilfe von Wattestäbchen. Hierbei wurden die inneren Organe vorsichtig auf die feuchten Tücher, welche sich auf den Wundrändern nach Bauchraumeröffnung befanden, mobilisiert und von innen umschlagen. Die Organe wurden beim Aufsuchen der linken Niere auf Tücher der rechten Bauchseite umgeschlagen. Nach Auffinden der linken Niere wurde die Gefäßklemme angelegt und somit die Blutzufuhr unterbunden. Der Zeitpunkt der Abklemmung wurde notiert. Nun wurde die rechte Niere aufgesucht und dabei die inneren Organe vorsichtig auf die linke Seite umgeschlagen. Nach Mobilisierung der rechten Niere wurde vorsichtig eine Ligatur um den Gefäßstiel gelegt. Anschließend wurde der gesamte Bauchraum mit einem in physiologischer Kochsalzlösung getränktem Tuch abgedeckt. Die Feuchthaltung wurde ständig aufrechterhalten um eine Austrocknung der inneren Organe zu vermeiden. 
Nach Ablauf der 40 Minuten („Timeralarm“) wurde die Gefäßklemme der linken Niere vorsichtig gelöst. Innerhalb der nächsten 2 Minuten mussten die folgenden Schritte absolviert werden: die rechte Niere musste zunächst wieder aufgesucht werden. Distal der Ligatur wurden $50 \mu \mathrm{l}$ der Injektionslösung (zellhaltig oder zellfrei, vorbehandelt oder nicht) mit Hilfe einer Insulinspritze injiziert. Die erfolgreiche Lage der Einstichstelle war anhand eines kleinen Blutungspunktes nach Zurückziehen der Nadel festzustellen. Direkt im Anschluss wurde die Ligatur zugezogen und die Niere entfernt. Die Fadenenden der nun um den Gefäßstiel befindlichen Ligatur wurden entsprechend auf ein Minimalmaß gekürzt. Dies musste, wie oben genannt, innerhalb von zwei Minuten nach Entfernung der Gefäßklemme erfolgen. Nun konnten die immer noch in feuchten Tüchern gelagerten inneren Organe vorsichtig in den Bauchraum mobilisiert werden bevor eine, erneut zweizeitige, Schließung des Bauchraumes folgte. Hier wurde zunächst die innere Muskelschicht mit einer fortlaufenden Naht verschlossen. Danach wurde die eröffnete Hautschicht mit einer fortlaufenden Naht geschlossen. Die erste Operation war mit diesem Schritt beendet und die Mäuse wurden vorsichtig auf Tücher in den Käfig gelegt. Futter und eine kleine Schale mit Wasser waren für die Zeit nach der Aufwachphase bedarfsgerecht mit in den Käfig gelegt. Die Mäuse befanden sich in der gesamten interoperativen Phase in tierpflegerischer Betreuung.

Die erste Operation simulierte eine akute Ischämie der Mäusenieren. Durch die Entfernung der rechten, zum Zeitpunkt der Operation noch gesunden Niere, wurde die Ischämie beidseitig simuliert. Die injizierten Zellen konnten nach Injektion nur noch im Gewebe der linken Niere wirken, nachdem sie über den Blutkreislauf dorthin gelangten. Die Nierenfunktion der Maus war nach der ersten Operation nur noch über die linke Niere gewährleistet. Die möglichen Auswirkungen der EPCs waren also hier zu untersuchen.

\subsubsection{Die Entnahme der Organe und des Blutes}

Der ausgewählte Zeitpunkt zur Entnahme der Organe von 48 Stunden nach der ersten Operation wurde aufgrund bereits durchgeführter Voruntersuchungen gewählt (Patschan et al. 2006a). Diese Voruntersuchungen ergaben, dass die Nierenfunktion der Mäuse nach akuter Ischämie 48 Stunden später am 
stärksten beeinträchtigt bzw. geschwächt war. Zur Entnahme der Organe und des Blutes war eine erneute Anästhesie mit ausreichender Tiefe erforderlich. Die Durchführung aller Schritte bis zur Eröffnung erfolgte wie bereits dargestellt. Der Bauchraum wurde diesmal lediglich mit einem T-Schnitt eröffnet. Die lateralen Extensionen waren hier unterhalb des Zwerchfells. Es musste darauf geachtet werden, eine vorzeitige Verletzung des Zwerchfells zu verhindern, da ansonsten die Blutentnahme aus dem schlagenden Herzen durch das Kollabieren des Pectorialraums nicht möglich gewesen wäre. Als erstes wurde das noch schlagende Herz durch das noch intakte Zwerchfell mit einer Insulinspritze punktiert. Jetzt konnte möglichst viel Blut entnommen werden. Hier waren $300 \mu l$ für die weiteren Untersuchungen ausreichend. Mit Hilfe des Blutes konnte in den folgenden Untersuchungen der Kreatininwert zur Ermittlung der Nierenfunktion bestimmt werden. Nach Blutentnahme wurde die Maus getötet und es konnte die Niere entnommen werden. Diese wurde noch am Operationstisch mit einem scharfen Skalpell in zwei Hälften geteilt und danach in die später beschriebenen Fixationslösungen gelegt.

\subsection{Erstellung von Gewebeschnitten für die mikroskopischen Untersuchungen}

Eine Hälfte der zuvor geteilten Organe wurde für die Herstellung von Dünnschnitten verwendet, die andere Hälfte zur Herstellung von Kryoschnitten. Die Dünnschnitte dienen der konventionellen histologischen Analyse. Mit Hilfe der Kryoschnitte erfolgte eine floureszenzhistologische Analyse.

Die Organhälfte für die Dünnschnitte musste, wie oben schon erwähnt, nach der Organentnahme in Formalin (Firma MERCK, Katalog Nr.: 103999 2500) gelegt werden. Dieses wurde zuvor mit einem Phosphatpuffer (Firma GIBCO, Katalog Nr.: 10010-015) verdünnt. Die Formalineinlegung der Organe fixiert deren Struktur und wirkt somit der nach Organentnahme eigentlich stattfindenden Autolyse bzw. Heterolyse der Organe entgegen. Somit werden die Gewebsstrukturen fixiert und postmortale Gewebszerfälle werden verhindert. Das Einbringen der Objekte in die Fixierungsflüssigkeit wird Immersionsfixierung genannt. Je größer die Oberfläche im Vergleich zum Volumen, desto rascher kann die Fixierlösung das Gewebe durchdringen und die Fixierergebnisse sind besser. Dies kann man durch das Schneiden des 
Präparates in Scheiben erreichen, am günstigsten sind senkrecht angeschnittene, ca. $5 \mathrm{~mm}$ große Stücke. Durch das Schneiden erreicht man zusätzlich, dass die Fixierlösung direkt dem Parenchym anliegt und nicht den erschwerten Weg über bindegewebige Membranen oder Organkapseln gehen muss. Formalin ist Fixierlösung und Konservierungsmittel zugleich. Durch die Fixierung wird die Enzymreaktion des Gewebes gestoppt und die Konservierung bewahrt den äußerlichen Zustand. Die Dauer der Fixierung sollte dabei immer nur so lang wie nötig sein, da man die Gefahr der brüchig werdenden Präparate, der Schrumpfung oder Quellung sowie des schlechten, späteren Anfärbens reduzieren möchte.

Bei den unterschiedlichen Geweben treten unterschiedliche Schrumpfungen und Quellungen bei der Fixierung auf. Je wasserreicher ein Gewebe ist, desto anfälliger ist es für die stattfindende Schrumpfung. An Grenzflächen unterschiedlicher Konsistenz kann es somit zu Zerreißungen und Abhebungen von der Unterfläche kommen. Dadurch kann man häufig Abhebungen des Epithels von seiner Unterlage beobachten. Das Parenchym und Kollagen sind in erster Linie durch Quellungen verändert.

Zur Herstellung der Dünnschnitte musste das Formalin zunächst wieder aus den Organen ausgewaschen werden. Für das Auswaschen der Fixierlösung gilt als Faustregel, dass man dieselbe Dauer wie beim Fixieren wählt. Im Falle des Formalins kann man die Auswaschung durch Verwendung von niedrigprozentigem Alkohol beschleunigen. Das Prozedere dauerte ca. 10 - 12 Stunden und wurde hier durch einen Gewebeinfiltrationsautomaten (LEICA TP1020) übernommen. Das Präparat wurde durch Xylol dehydriert und anschließend in der Ausgießstation (Tissue Block Dispenser PAG 12, MEDITE MEDIZINTECHNIK) in Paraffin eingebettet.

Paraffine sind Mischungen aus gesättigten Kohlenwasserstoffen. Ihr Schmelzpunkt steigt mit zunehmender Kettenlänge. Ein höherer Schmelzpunkt führt zur steigenden Konsistenz des erstarrten Paraffins. In histologischen Routinearbeiten wählt man einen Schmelzpunkt zwischen $56^{\circ}-58^{\circ} \mathrm{C}$. Paraffin bildet beim Erstarren Kristalle, die umso feiner sind je rascher das Abkühlen erfolgt. 
Hierbei war zu beachten, dass die zu schneidende Organfläche auf dem Boden der Einbettkassette lag. Es musste nun auf $2^{\circ} \mathrm{C}$ abgekühlt werden. Die Entwässerung mit einer aufsteigenden Alkoholreihe vor der Paraffineinbettung der Organe war aufgrund der Wasserunlöslichkeit des Parrafins notwendig. Die anschließende Alkoholentfernung geschieht durch obengenanntes Xylol.

Das Entwässern entzieht dem fixierten Gewebe Wasser und führt zur erneuten Schrumpfung. Dies ist vor der Einbettung in wasserunlöslichen Medien wie Paraffinen notwendig. Die Entwässerung sollte wie oben erwähnt stufenweise vorgenommen werden um Zerreißungen und zu starke Schrumpfungen zu vermeiden. Gewöhnlich wird dies schrittweise in 50\%-, 60\%-, 70\%-, 80\%- und 96\%-igen Alkohol durchgeführt, bevor die Entwässerung anschließend in reinem Alkohol abgeschlossen wird. Im günstigsten Fall heben sich diese Schrumpfung und die davor erfolgten Quellungen auf. Die möglichen oben genannten Zerreißungen während des Fixierens sind aber nicht mehr reparabel.

Die zur Untersuchung notwendigen Schnitte hatten eine Dicke von 5-7 $\mu \mathrm{m}$. Hergestellt wurden sie mit Hilfe eines Autocut Microtom (LEICA Reichert-Jung 2040). Beim Schneiden der Paraffinblöcke verwendet man trockene Messer. Bei zu weichem Paraffin würde sich der Schnitt zusammenschieben. Ist es jedoch zu hart, besteht die Gefahr, dass sich der Schnitt zusammenrollt oder gar in Splitter zerfällt. Um dies zu vermeiden, kühlt man zu weiches Paraffin mit Eiswürfeln ab oder man wählt bei zu hartem Paraffin eine dünnere Schnittdicke mit einem leicht erwärmten Messer.

Nachdem die Schnitte hergestellt worden waren, mussten sie mit Hilfe eines Pinsels vorsichtig abgehoben und in ein Wasserbad gelegt werden. Das Wasserbad hatte eine Temperatur von $50-55^{\circ} \mathrm{C}$. In diesem Milieu konnten sich die Schnitte entfalten und nun mit einem sauberen, fettfreien Objektträger aufgenommen um auf einer Trockenplatte (AP-Thermoplatte) bei $40^{\circ} \mathrm{C}$ getrocknet zu werden.

Die Dünnschnitte dieser Arbeit wurden mit einer PAS (Perjodsäure-SchiffReaktion) angefärbt. Diese Färbung beruht auf der Darstellung von zwei dichtgelagerten Aldehydgruppen mit Hilfe der fuchsinschwefeligen Säure. Die Perjodsäure hydrolisiert zuvor die Kohlenhydrate zu Aldehydgruppen. Die 
resultierende Färbung der Kerne ist hier dunkelblau, die der sauren Mukopolysaccharide blau und die Färbung der neutralen Mukopolysaccharide rosarot. Auch Zerebroside, Ganglioside, Mukoproteine und Glykoproteine sind mit dieser Färbung aufgrund einer positiven Reaktion darstellbar.

Vor Einfärbung mussten die Schnitte entparaffinisiert werden. Dies geschah mittels Xylol und einer nun absteigenden Alkoholreihe. Nachdem die Schnitte paraffinfrei waren, konnten sie mit destilliertem Wasser abgespült und für 3 Minuten in 3\%-ige Essigsäure gelegt werden. Die Dünnschnitte wurden anschließend 30 Minuten mit Alcinblau inkubiert. Im Anschluss erfolgte eine mehrstufige Abspülung in folgender Reihenfolge: destilliertes Wasser, 5 Minuten Leitungswasser, destilliertes Wasser.

Nach der Abspülung wurden die Dünnschnitte für 10 Minuten in frisch angesetzte 1\%-ige Perjodsäure gelegt und anschließend wieder mit destilliertem Wasser abgespült. Nun folgte eine 15-minütige Behandlung der Schnitte mit dem Schiffschen Reagenz und der darauffolgenden, dreimaligen 2-minütigen Sulfidwasserbehandlung. Ein erneutes Spülen mit Leitungswasser von 5 - 10 Minuten und Aqua dest. war vor Inkubation mit Hämalaun-Lösung nach Meyer nötig. Die folgende Abspülung erfolgte mit destilliertem Wasser. Nun wurden die Schnitte für 10 Minuten mit Leitungswasser gebläut und im letzten Schritt der Färbung wieder mit Aqua dest. entwässert um schließlich eingedeckt zu werden.

Die Eindeckung mit einem Tropfen Eindeckmedium und der Fixierung mit einem Deckglas ermöglicht die mikroskopische Untersuchung und Konservierung des Schnitts. Dadurch sollen die Schnittpräparate durchsichtig erhalten und die Struktur und Färbung nicht beschädigt werden. Bei der Eindeckung ist zu beachten, dass Lufteinschlüsse und Mediumüberstände vermieden bzw. entfernt werden.

Die Herstellung der oben genannten Alcinblau-Lösung gelang durch Lösung von $1 \mathrm{~g}$ Alcinblau 8 GS (wasserlöslich) in $1000 \mathrm{ml}$ 3\%-iger Essigsäure. Das verwendete Schiffschen-Reagenz wurde aus zwei Lösungen ( $A$ und $B$ ) hergestellt. Lösung A bestand aus $5 \mathrm{~g}$ Pararosanilin in $150 \mathrm{ml} \mathrm{1-M-HCl} \mathrm{gelöst.}$ Lösung B bestand aus $5 \mathrm{~g}$ Kalium- oder Natriumdisulfid, in $850 \mathrm{ml}$ demineralisiertem Wasser gelöst. Diese Lösungen wurden gemischt und bei Raum- 
temperatur in einem abgedunkelten Raum stehen gelassen. Am nächsten Tag wurde dem Gemisch $30 \mathrm{~g}$ Aktivkohle hinzugegeben um anschließend für 15 Minuten kräftig geschüttelt und filtriert zu werden. Das entstandene, farblose Filtrat wurde in eine braune Flasche gegeben und im Kühlschrank aufbewahrt.

Mit Hilfe der oben beschriebenen Färbemethode wurde der akute tubuläre Schaden der untersuchten Nieren semiquantitativ jeweils für die Parameter Vakuolisierung, Epithelabflachung, Detritus, Kernverlust sowie Bürstensaumverlust wie folgt bewertet:

- Grad 0: nicht vorhanden

- Grad 1: geringfügig ausgebildet

- Grad 2: mäßig ausgebildet

- Grad 3: stark ausgebildet

Anschließend wurde für jeden einzelnen Parameter ein Mittelwert ermittelt.

\subsection{Dünnschnitte für die Immunfluoreszenzhistologie}

Für die Untersuchung mit Hilfe der Immunfluoreszenzhistologie wurden die anderen entnommenen Organhälften der Mäuse verwendet. Aus diesem Organhälften wurden Kryoschnitte hergestellt und untersucht. Nach Entnahme wurden die Organe zunächst ebenfalls für eine Stunde in Formalin gelegt. Anschließend wurden sie jedoch für diese Untersuchungsmethode in $30 \%$-ige Saccharose-Lösung eingelegt. Dort verweilten sie für mindestens 12, jedoch maximal 48 Stunden bei $4^{\circ} \mathrm{C}$ im Kühlschrank. Im Anschluss erfolgte die Einbettung der Organe in Tissue Tek (Firma Sakura OCT, Katalog Nr.: 4583) und Aufbewahrung bei $-80^{\circ} \mathrm{C}$.

Die Schnitte in der gewünschten Dicke von 5-7 $\mu \mathrm{m}$ wurden mit Hilfe eines Gefriermikrotoms (Firma Leica, Jung CM 3000) hergestellt. Danach wurden die Schnitte auf zuvor mit Eiweißglycerin (Firma Roth, Art. Nr.: P04.1) beschichtete Objektträger aufgebracht. Wurden anschließend keine immunhistochemischen Färbungen durchgeführt, erfolgte die Aufbewahrung bei $-20^{\circ} \mathrm{C}$.

Vor der eigentlichen Floureszenzmarkierung mussten die Objektträger für 30 Minuten in PBS-BSA 1\% (Bovine Serum Albumin, Firma PAA, Katalog Nr.: K41001) gelegt werden. Im Anschluss daran wurden die Schnitte vorsichtig 
getrocknet. Danach wurde mit Nagellack der Schnitt vorsichtig umkreist. Dieses Vorgehen sollte ein Verschwimmen der in der weiteren Behandlung aufpipettierten Flüssigkeiten auf dem Objektträger vermeiden.

Die Inkubation der Schnitte mit dem Antikörper (FITC anti-mouse CD117(c-Kit), Firma BD, Katalog Nr.: 553354) konnte nun erfolgen. Zuvor wurde der Antikörper im Verhältnis 1:1000 in PBS (Firma Gibco) verdünnt. Die Antikörperinkubation wurde über Nacht durchgeführt und dauerte mindestens 12 Stunden. Die Lagerung der slides erfolgte ab diesem Zeitpunkt in einer feuchten Kammer bei $-4^{\circ} \mathrm{C}$.

Vor der Zellmarkierung mussten die Objektträger zunächst 3-mal mit PBS gewaschen werden. Die Anfärbung der Kerne erfolgte durch 10-minütige Inkubation mit DAPI-Lösung (Firma MiBi-Tec, Katalog Nr.: D1306). DAPILösung wurde zuvor mit PBS im Verhältnis 1:50 verdünnt. Bevor die abschließende Eindeckung der nun gefärbten und antikörpermarkierten Schnitte erfolgen durfte, war eine erneute dreimalige Waschung in PBS nötig. Nach Eindeckung mit Flourescence Mounting Medium (Firma DAKO, Katalog Nr.: S3023) wurden die Schnitte bis zur später durchgeführten Floureszenzmikroskopie bei $4-8^{\circ} \mathrm{C}$ aufbewahrt.

Zur Auswertung der Organschnitte wurden je 10 Gesichtsfelder der Nierenrinde und 5 Gesichtsfelder des Nierenmarks sowie der Nierenpapille auf die Präsenz von $\mathrm{C}-K i t+/$ cell tracker ${ }^{8}+$ Zellen analysiert. Dies erfolgte mit Hilfe eines Fluoreszenzmikroskops (ZEISS, Axiovert S 100 TV) bei 40-facher Vergrößerung. Potentielle c-Kit+ Zellen führten durch die Markierung von c-Kit zu einer grünen Floureszenz. Konnte gleichzeitig eine rote Floureszenz (Cell Tracker $\left.{ }^{\circledR}\right)$ nachgewiesen werden, musste von der Anwesenheit der zuvor injizierten EPCs im Nierengewebe ausgegangen werden. Hierbei erfolgte die Auswertung hinsichtlich der Anzahl nachgewiesener Zellen pro Gesichtsfeld.

\subsection{Serumkreatininbestimmung}

Kreatinin ist ein Stoffwechselprodukt des Vertebratenorganismus. Es wird im Muskel aus Kreatinphosphat gewonnen und muss als harnpflichtiges Stoffwechselprodukt über die Nieren ausgeschieden werden (Horn 2009). Es erscheinen beim Menschen circa 1,0 - 1,5 g Kreatinin täglich im Endharn. Das 
Kreatinin gelangt fast ausschließlich durch die glomeruläre Filtration in den Harn, und es wird nicht resorbiert. Die tubulär sezernierte Menge fällt bei der gesunden Niere gegenüber der glomerulär filtrierten nicht ins Gewicht (Rehner und Daniel 2010). Der Blutplasmaspiegel des Kreatinins hängt von zahlreichen Faktoren ab, besonders von der Muskelmasse (Rehner und Daniel 2010) und der Nierenfunktion selbst. So kommt es zu einem Anstieg des Kreatininspiegels im Blut, wenn die Niere durch eine Funktionsminderung von ca. 50\%-60\% betroffen ist und die glomerulätre Filtrationsrate (GFR) stark eingeschränkt ist (Brandenburger und Bajorat 2006; Siegenthaler und Blum 2006). Die Kreatininkonzentration ist daher immer noch der Standardparameter zur Beurteilung der Nierenfunktion.

Zur Bestimmung der Serumkreatininwerte wurden das Testverfahren 'LT-SYS' der Firma "Labor und Technik Eberhard Lehmann" (Creatinin PAP, enzymatisch, flüssig, Bestellnummer: LT-CR 0101) sowie ein Photometer (Schimadzu Spectrophotometer UV-120-01) verwendet. Die benötigten Reagenzien wurden gebrauchsfertig geliefert (Reagenz 1: EHSPT 0,4 mmol/l, Creatinase $>10 \mathrm{kU} / \mathrm{l}$, Sarcosinoxidase $>3,5 \mathrm{kU} / \mathrm{l}$, Ascorbinatoxidase $>1 \mathrm{kU} / \mathrm{l}$; Reagenz 2: 4-Aminoantipyrin 2,95 mmol/l, Peroxidase $>4 \mathrm{kU} / \mathrm{l}$, Creatininase $>$ 150 kU/I). Vom Reagenz 1 wurden für jede Probe, Leerprobe und Standard $600 \mu \mathrm{l}$ benötigt.

Die Serumproben mussten in einem 1,5 ml Eppendorf-Röhrchen im Verhältnis 1:5 bis 1:10 mit destilliertem Wasser verdünnt werden. Als Zielvolumen einer jeden Probe waren $50 \mu \mathrm{l}$ vorgesehen. Somit wurden also $10 \mu \mathrm{l}$ Serum jeweils mit $40 \mu \mathrm{l}$ destilliertem Wasser verdünnt respektive $5 \mu \mathrm{l}$ Serum mit je $45 \mu \mathrm{l}$ destilliertem Wasser vermischt. Zusätzlich wurden $50 \mu \mathrm{l}$ der KreatininStandardlösung (Kreatinin 2,00 mg/dl) in ein weiteres $1,5 \mathrm{ml}$ EppendorfRöhrchen gegeben. Im Wasserbad wurden die Proben anschließend auf $37^{\circ} \mathrm{C}$ erwärmt.

Für die Untersuchung wurden 3 Photometer-Küvetten gefüllt. Die erste wurde mit $50 \mu \mathrm{l}$ der mit destilliertem Wasser verdünnten Serumprobe sowie $600 \mu \mathrm{l}$ Reagenz 1 gefüllt. In der zweiten Photometer-Küvette befanden sich $50 \mu \mathrm{lder}$ Kreatinin-Standardlösung mit $600 \mu \mathrm{l}$ Reagenz 1. Die dritte Küvette wurde als Leerprobe lediglich mit $600 \mu \mathrm{l}$ Reagenz 1 gefüllt. Die drei Küvetten wurden jeweils gut gemischt und für 3 Minuten bei $37^{\circ} \mathrm{C}$ inkubiert. Anschließend wurden 
jeder Küvette $200 \mu \mathrm{l}$ der Reagenz 2 hinzugegeben. Jede Küvette wurde erneut gemischt und weiterhin bei $37^{\circ} \mathrm{C}$ inkubiert.

Die erste Absorptionsmessung zur Ermittlung des ersten Extinktionswertes E1 wurde ca. 90 Sekunden nach Zugabe von Reagenz 2 vorgenommen. Die Wellenlänge betrug $550 \mathrm{~nm}$. Die notwendige zweite Absorptionsmessung erfolgte weitere 120 Sekunden nach Messung von E1. E2 wurde ebenfalls bei $550 \mathrm{~nm}$ gemessen.

Die Ermittlung des Serumkreatininwertes erfolgt mit Hilfe der folgenden Formel.

Serumkreatininwert $=$ Sollwert des Standards $\times\left(\left(\mathrm{dE}_{\text {Analyse }}\right) /\left(\mathrm{dE}_{\text {Standard }}\right)\right)$

mit $\quad \mathrm{dE}=\mathrm{E} 2-\mathrm{E} 1$

\subsection{Statistische Auswertung}

Im Rahmen dieser Auswertung wurde der Mann-Whitney-Test zur Beurteilung von statistisch signifikanten Unterschieden zwischen den Tieren der verschiedenen Gruppen herangezogen. Bei einem $p$-Wert $<0,05$ wurde Siginifikanz postuliert. 


\section{Ergebnisse}

\subsection{Darstellung der verschiedenen Versuchsgruppen}

In dieser Arbeit wurden Mäuse in 5 verschiedenen Versuchsgruppen untersucht. In der ersten Gruppe wurde den Mäusen lediglich Blut entnommen und der Kreatininwert bestimmt. Diese Gruppe diente als Kontrollkollektiv für die nachfolgenden 4 Gruppen. Es war somit von einem physiologischen Wert einer Maus dieser Population ohne Ischämie und ohne medikamentöse Behandlung auszugehen.

Die Mäuse der nachfolgenden Gruppen wurden alle einer 40-minütigen Ischämie unterzogen und anschließend mit den zu untersuchenden Stoffgruppen injiziert. In der zweiten Gruppe wurde physiologische Kochsalzlösung verwendet, in Gruppe 3 wurden $0,5 \times 10^{6}$ unbehandelte EPCs injiziert und in den Gruppen 4 und 5 je $0,5 \times 10^{6}$ EPCs nach einstündiger Inkubation in Angiopoetin-2-haltigem Zellmedium (400 oder $800 \mathrm{ng} / \mathrm{ml}$ ).

\subsection{Nierenfunktionsanalyse}

\subsubsection{Erste Gruppe}

Die statistischen Werte einer kollektiven Kontrollgruppe ohne Ischämie in Zusammenarbeit mit den Dres. Rinneburger und Hildebrandt betrugen für den Mittelwert 0,09 mg/dl, bei einem SEM von 0,02 mg/dl.

\subsubsection{Zweite Gruppe}

Den Mäusen dieser Gruppe wurden nach 40-minütiger Ischämie $50 \mu \mathrm{l} \mathrm{NaCl}$ injiziert, inklusive der bereits beschriebenen kontralateralen Nephrektomie. Der Mittelwert lag hier bei $0,47 \mathrm{mg} / \mathrm{dl}$, bei einem SEM von $0,06 \mathrm{mg} / \mathrm{dl}$.

\subsubsection{Dritte Gruppe}

In dieser Gruppe wurden den Mäusen nach 40-minütiger Ischämie mit kontralateraler Nephrektomie $0,5 \times 10^{6}$ EPCs injiziert. Der Mittelwert lag bei 0,74 $\mathrm{mg} / \mathrm{dl}$, bei einem SEM von 0,22 mg/dl. 


\subsubsection{Vierte Gruppe}

Die Konzentration der mit Angiopoetin-2 vorbehandelten EPCs betrug in dieser Gruppe $400 \mathrm{ng} / \mathrm{ml}$. Der Mittelwert der Serumkreatininbestimmung lag hier nach der OP bei 0,27 mg/dl, bei einem SEM von $0,04 \mathrm{mg} / \mathrm{dl}$.

\subsubsection{Fünfte Gruppe}

Die Konzentration des Ang-2 in dieser Gruppe wurde auf $800 \mathrm{ng} / \mathrm{ml}$ erhöht. Es muss auch hinsichtlich der statistischen Werte erwähnt werden, dass alle Mäuse nach erfolgter OP sehr schwach waren. Sofern sie die erste OP überlebten und auch nicht nach Anästhesie vor der zweiten OP oder im Zuge der zweiten OP verstarben, bestätigten die folgenden Serumkreatininwerte den schwachen und labilen Zustand der Mäuse. Der Mittelwert des Serumkreatinins bei noch möglicher Blutabnahme lag bei $2,51 \mathrm{mg} / \mathrm{dl}$, bei einem SEM von 0,76 $\mathrm{mg} / \mathrm{dl}$. Die Blutentnahme war hier unter erschwerten Bedingungen nur bei 4 Mäusen möglich.

Die Resultate der Nierenfunktionsanalyse zum Zeitpunkt 48 Stunden nach Operation seien im Folgenden tabellarisch und graphisch dargestellt: 


\begin{tabular}{|c|c|c|c|c|c|c|}
\hline Maus & \multicolumn{7}{|c|}{ Kreatininwerte in mg/dl } \\
\hline & Kontrolle & NaCl & EPCs & $\begin{array}{c}\text { (EPCs+Ang- } \\
\mathbf{2 . 1}\end{array}$ & $\begin{array}{c}\text { EPCs+Ang- } \\
\mathbf{2 . 2}\end{array}$ & $\begin{array}{c}\text { EPCs+Ang- } \\
\mathbf{2 . 4}\end{array}$ \\
\hline 1 & 0,09 & 0,30 & 0,42 & 0,84 & 0,33 & 0,84 \\
\hline 2 & 0,11 & 0,82 & 0,45 & 0,26 & 0,1 & 2,93 \\
\hline 3 & 0,06 & 0,45 & 1,53 & 0,43 & 0,33 & 4,4 \\
\hline 4 & 0,03 & 0,31 & 0,91 & 0,46 & 0,26 & 1,88 \\
\hline 5 & 0,17 & 0,35 & 0,38 & 0,29 & 0,23 & ${ }^{*}$ \\
\hline 6 & & 0,56 & $*$ & & 0,38 & ${ }^{*}$ \\
\hline 7 & & 0,47 & & & & $\mathbf{0 , 2 7}$ \\
\hline $\begin{array}{c}\text { Mittel- } \\
\text { wert }\end{array}$ & $\mathbf{0 , 0 9}$ & $\mathbf{0 , 4 7}$ & $\mathbf{0 , 7 4}$ & $\mathbf{0 , 4 6}$ & $\mathbf{2 , 5 1}$ \\
\hline SEM & $\mathbf{0 , 0 2}$ & $\mathbf{0 , 0 6}$ & $\mathbf{0 , 2 2}$ & $\mathbf{0 , 1 5}$ & $\mathbf{0 , 0 4}$ & $\mathbf{0 , 7 6}$ \\
\hline
\end{tabular}

Tabelle 1: Tabellarische Darstellung der Resultate. Legende für die Angiopoetin-2 Konzentrationen: Ang-2.1 - (200 ng/ml), Ang-2.2 - (400 ng/ml), Ang-2.4 - (800 ng/ml). Die ebenfalls aufgeführte Ang-2.1-Gruppe entstammt der bereits verteidigten Doktorarbeit von Herrn Dr. J. Rinneburger. Die Kontrollgruppe entstammt den kollektiven Vorarbeiten in Zusammenarbeit mit den Dres. A. Hildebrandt und J. Rinneburger. Der Vollständigkeit halber werden die Werte hier dargestellt. * bedeutet: es war für die Untersuchung keine ausreichende Blutmenge zu entnehmen.

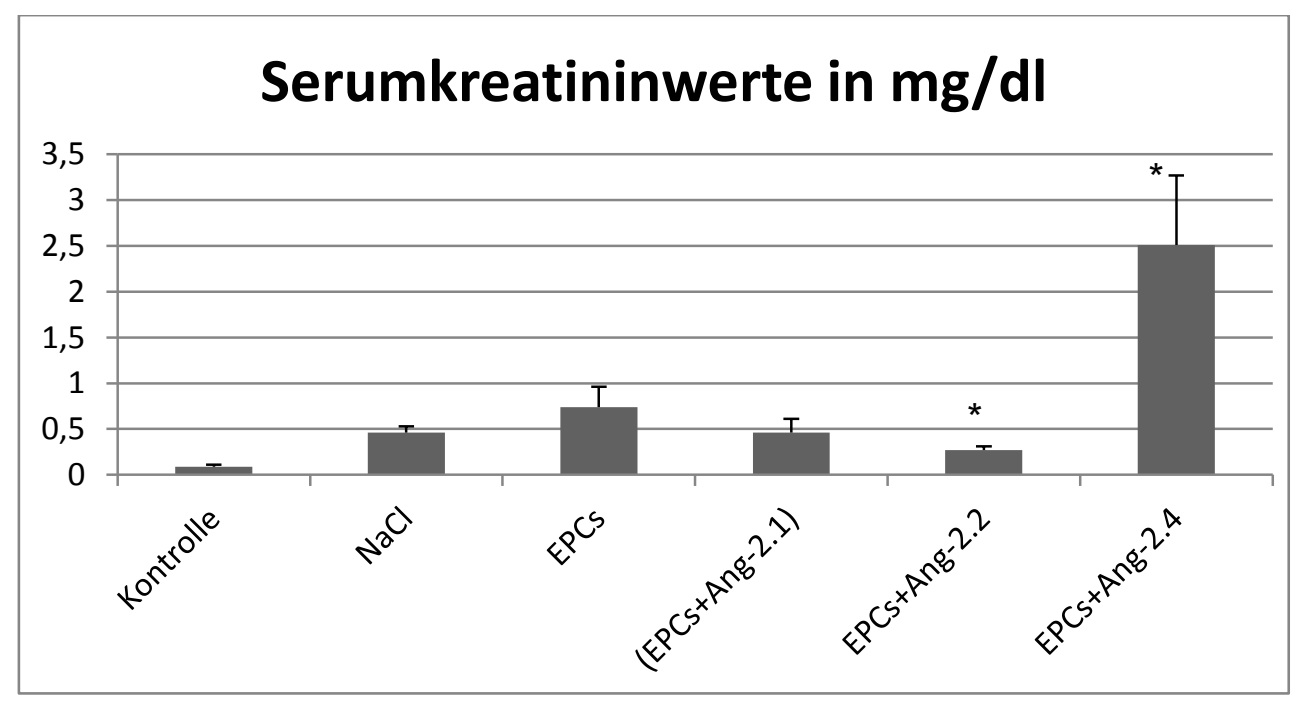

Abbildung 1: Serumkreatininwerte als Mittelwerte und SEM in den untersuchten Gruppen, *:p<0,05; Es liegt eine signifikante Kreatininwerterhöhung in der Gruppe EPCs+Ang-2.4 (Gruppe 5) und eine signifikante Kreatininwerterniedrigung in der Gruppe EPCs+Ang-2.2 (Gruppe 4) vor. Die ebenfalls aufgeführte Ang-2.1-Gruppe entstammt der bereits verteidigten Doktorarbeit von Herrn Dr. J. Rinneburger. Der Vollständigkeit halber werden die Werte hier dargestellt. 


\subsection{Konventionelle Nierenmorphologie}

Für die histologische Untersuchung der Nieren wurden die Gewebeschnitte mit Hilfe der PAS-Methode angefärbt. Beurteilt wurden die Gewebeproben anhand der folgenden Parameter:

- $\quad$ die Abflachung der Tubulusepithelzellen

- $\quad$ Kernverlust der Tubulusepithelzellen

- $\quad$ Detritus

- Vakuolisierung der Tubulusepithelzellen

- Verlust des Bürstensaums der Tubulusepithelzellen

Die Bewertung dieser einzelnen Parameter erfolgte in 4 Graden:

- $\quad$ Grad 0: nicht vorhanden

- $\quad$ Grad 1: geringfügig ausgebildet

- $\quad$ Grad 2: mäßig ausgebildet

- $\quad$ Grad 3: stark ausgebildet

Die histologische Untersuchung der verschiedenen Gruppen [EPCs (Gruppe 3), EPCs+Ang-2.2 (Gruppe 4) sowie EPCs+Ang-2.4 (Gruppe 5)] zeigte signifikante Unterschiede in allen oben genannten Parametern Detritus, Kernverlust, Bürstensaumverlust, Vakuolisierung und Epithelabflachung. Der mittlere Gesamtpunktwert aus diesen Parametern zeigte ebenfalls signifikante Unterschiede innerhalb der drei Gruppen (Tabellen 2-7, Abbildungen 2-7). Der verringerte histologische Nierenschaden in der Gruppe EPCs+Ang-2.2 (Gruppe 4) deckt sich mit den niedrigen Serumkreatininwerten aus der Nierenfunktionsanalyse (Tabelle 1, Abbildung 1). 


\begin{tabular}{|c|c|c|c|}
\hline & $\begin{array}{l}0,5 \times 10^{6} \text { EPCs } \\
\text { (Gruppe 3) }\end{array}$ & $\begin{array}{l}0,5 \times 10^{6} \text { EPCs + } \\
\text { Ang-2.2 } \\
\text { (Gruppe 4) }\end{array}$ & $\begin{array}{l}0,5 \times 10^{6} \text { EPCs + } \\
\text { Ang-2.4 } \\
\text { (Gruppe 5) }\end{array}$ \\
\hline \multicolumn{4}{|l|}{ Versuchstier } \\
\hline 1 & 1 & 1 & 1 \\
\hline 2 & 2 & 0 & 1 \\
\hline 3 & 2 & 2 & 2 \\
\hline 4 & 2 & 0 & 1 \\
\hline 5 & 1 & 0 & 2 \\
\hline 6 & 1 & 0 & 1 \\
\hline
\end{tabular}

Tabelle 2: Epithelabflachung in den Graden 0-3

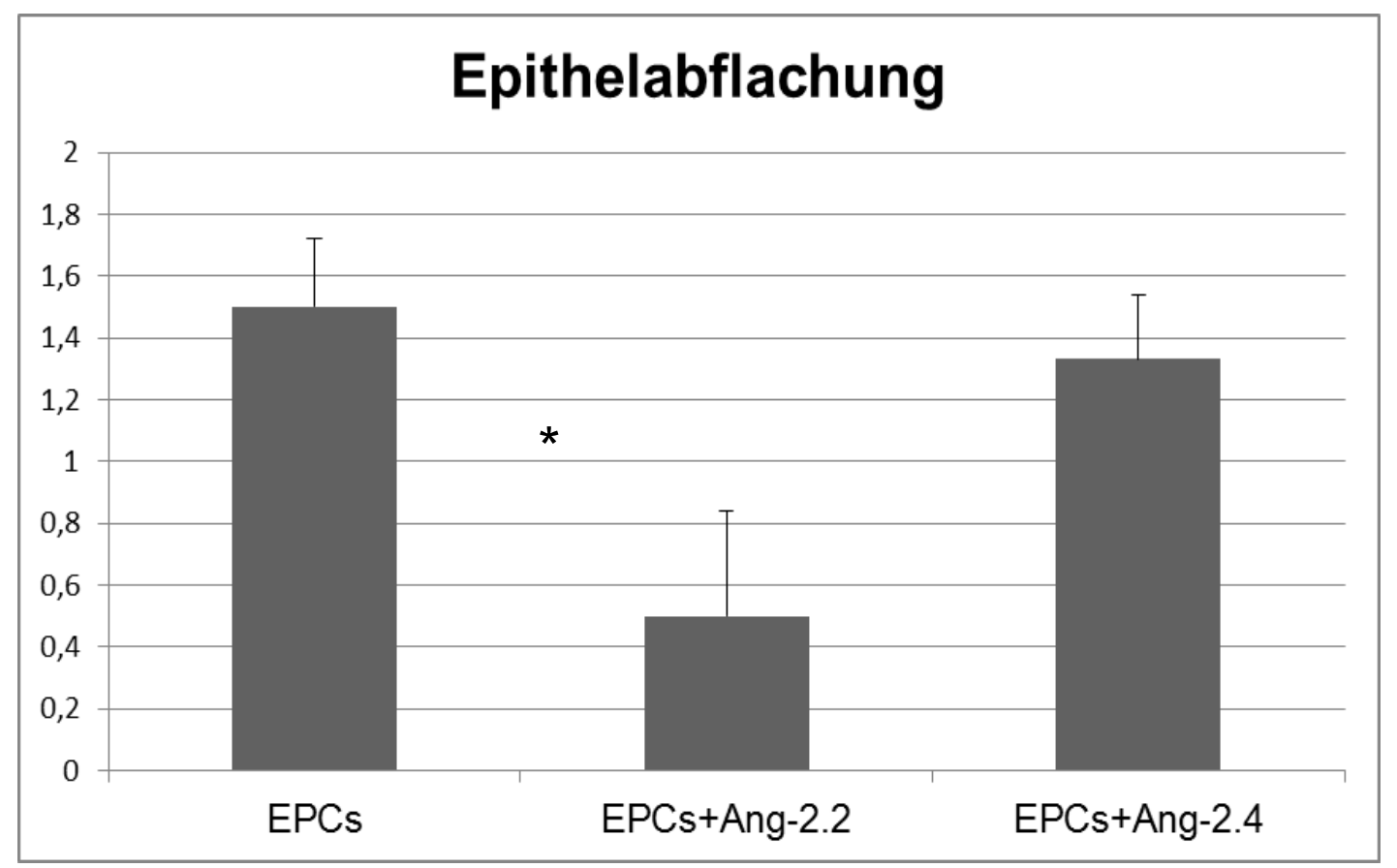

Abbildung 2: Epithelabflachung; Ergebnisse als Mittelwerte und SEM, *: $p<0,05$; Es zeigt sich eine signifikante Verminderung einer Epithelabflachung in der Gruppe EPCs+Ang-2.2 (Gruppe 4) gegenüber der Gruppe EPCs (Gruppe 3). 


\begin{tabular}{|c|c|c|c|}
\hline & $\begin{array}{l}0,5 \times 10^{6} \text { EPCs } \\
\text { (Gruppe } 3 \text { ) }\end{array}$ & $\begin{array}{l}0,5 \times 10^{6} \text { EPCs + } \\
\text { Ang-2.2 } \\
\text { (Gruppe 4) }\end{array}$ & $\begin{array}{l}0,5 \times 10^{6} \text { EPCs + } \\
\text { Ang-2.4 } \\
\text { (Gruppe 5) }\end{array}$ \\
\hline \multicolumn{4}{|l|}{ Versuchstier } \\
\hline 1 & 0 & 1 & 1 \\
\hline 2 & 0 & 0 & 1 \\
\hline 3 & 0 & 1 & 3 \\
\hline 4 & 1 & 0 & 1 \\
\hline 5 & 2 & 0 & 2 \\
\hline 6 & 1 & 0 & 1 \\
\hline
\end{tabular}

Tabelle 3: Detritus in den Graden 0-3

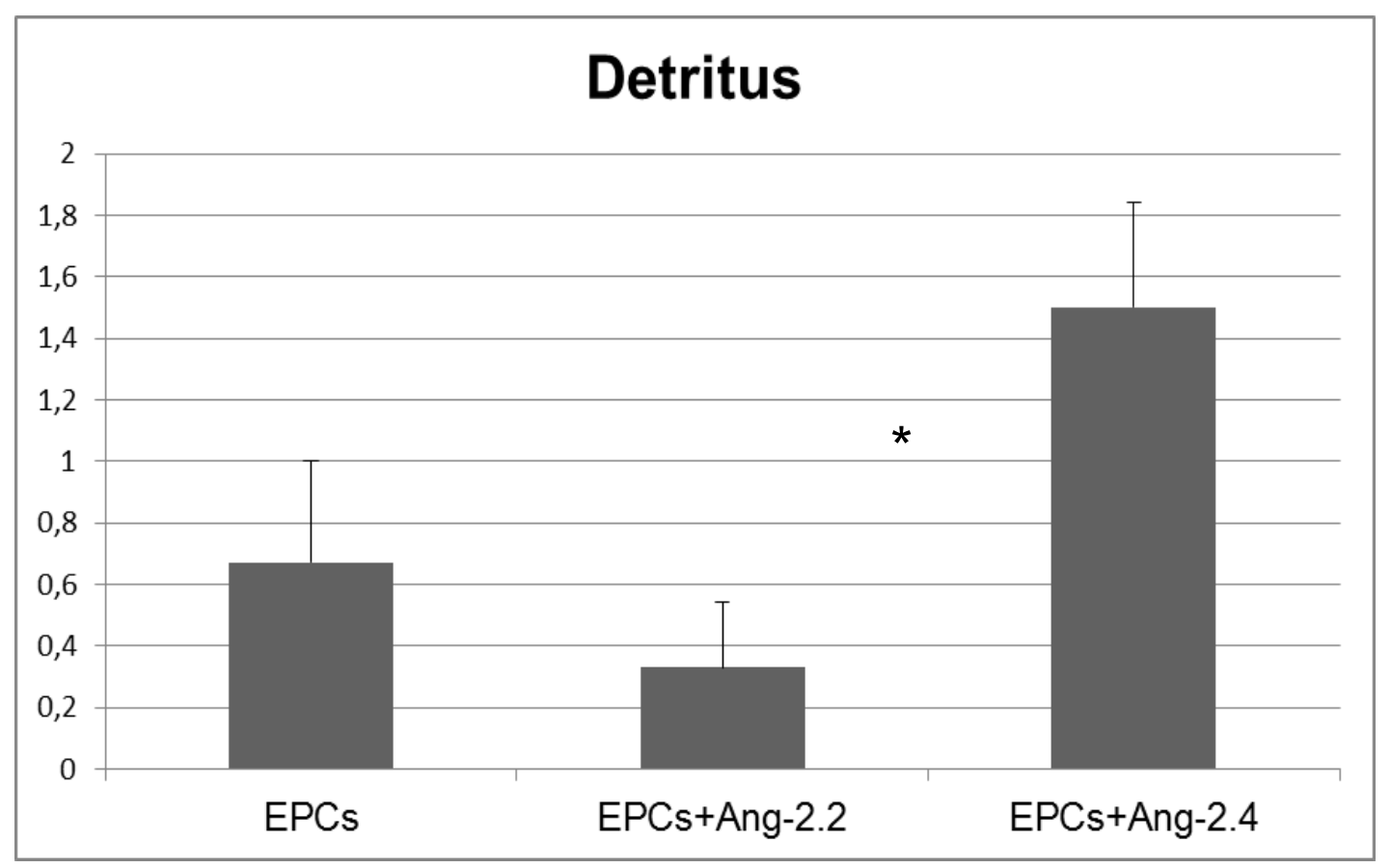

Abbildung 3: Detritus; Ergebnisse als Mittelwerte und SEM, *: $p<0,05$; Es zeigt sich eine signifikante Detritusverminderung in der Gruppe EPCs+Ang-2.2 (Gruppe 4) im Vergleich zur Gruppe EPCs+Ang-2.4 (Gruppe 5). 


\begin{tabular}{|c|c|c|c|}
\hline & $\begin{array}{l}0,5 \times 10^{6} \text { EPCs } \\
\text { (Gruppe 3) }\end{array}$ & $\begin{array}{l}0,5 \times 10^{6} \text { EPCs + } \\
\text { Ang-2.2 } \\
\text { (Gruppe 4) }\end{array}$ & $\begin{array}{l}0,5 \times 10^{6} \text { EPCs + } \\
\text { Ang-2.4 } \\
\text { (Gruppe 5) }\end{array}$ \\
\hline \multicolumn{4}{|l|}{ Versuchstier } \\
\hline 1 & 0 & 1 & 1 \\
\hline 2 & 0 & 0 & 1 \\
\hline 3 & 0 & 1 & 3 \\
\hline 4 & 1 & 0 & 1 \\
\hline 5 & 2 & 0 & 3 \\
\hline 6 & 1 & 0 & 1 \\
\hline
\end{tabular}

Tabelle 4: Kernverlust in den Graden 0-3

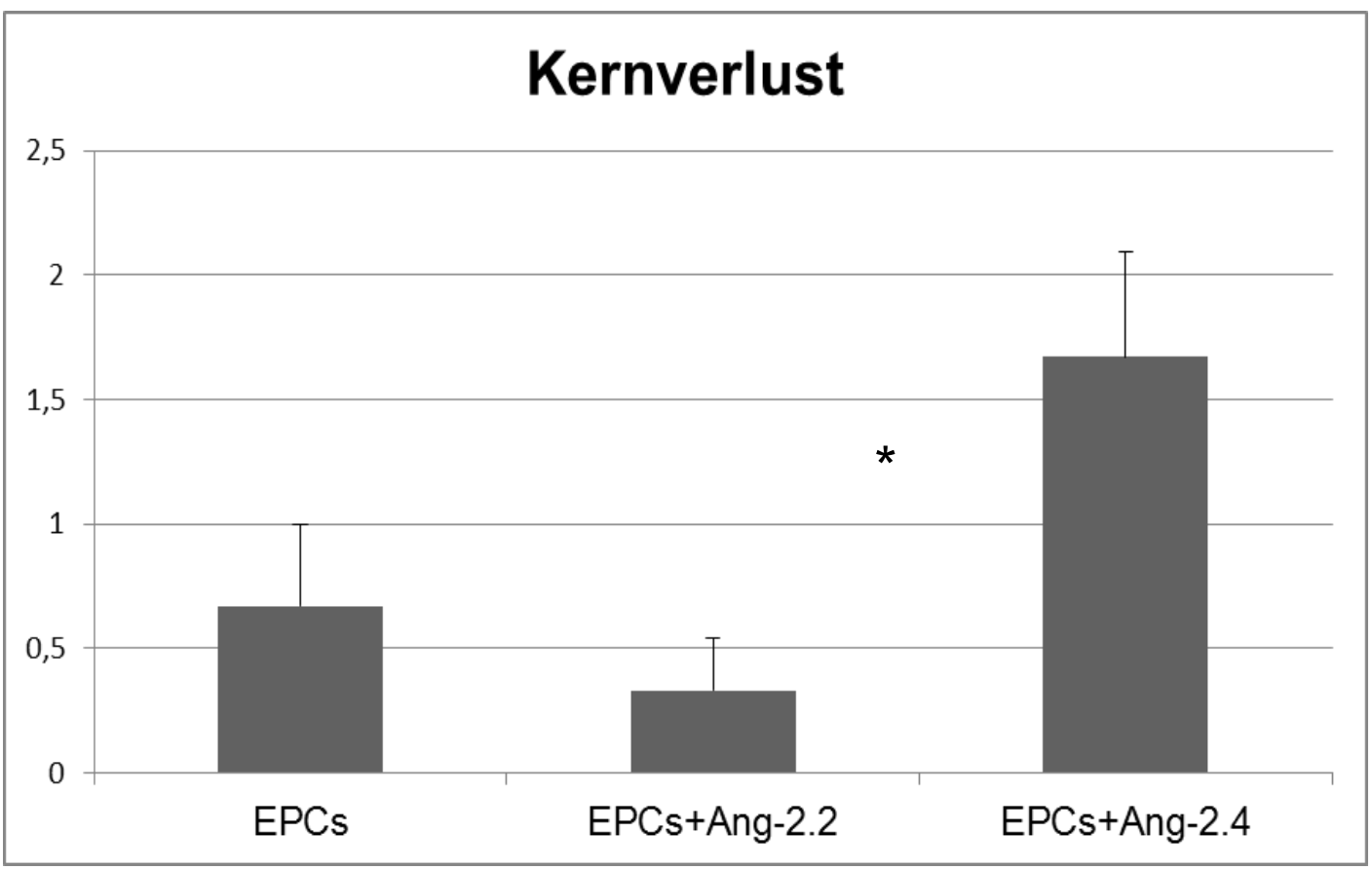

Abbildung 4: Kernverlust; Ergebnisse als Mittelwerte und SEM, *: $p<0,05$; Es zeigt sich ein signifikant geringerer Kernverlust in der Gruppe EPCs+Ang-2.2 (Gruppe 4) im Vergleich zur Gruppe EPCs+Ang-2.4 (Gruppe 5). 


\begin{tabular}{|c|c|c|c|}
\hline & $\begin{array}{l}0,5 \times 10^{6} \text { EPCs } \\
\text { (Gruppe 3) }\end{array}$ & $\begin{array}{l}0,5 \times 10^{6} \text { EPCs + } \\
\text { Ang-2.2 } \\
\text { (Gruppe 4) }\end{array}$ & $\begin{array}{l}0,5 \times 10^{6} \text { EPCs + } \\
\text { Ang-2.4 } \\
\text { (Gruppe 5) }\end{array}$ \\
\hline \multicolumn{4}{|l|}{ Versuchstier } \\
\hline 1 & 0 & 1 & 1 \\
\hline 2 & 0 & 0 & 1 \\
\hline 3 & 2 & 1 & 3 \\
\hline 4 & 1 & 0 & fehlt \\
\hline 5 & 1 & 0 & 1 \\
\hline 6 & 1 & 0 & 2 \\
\hline
\end{tabular}

Tabelle 5: Vakoulisierung in den Graden 0-3

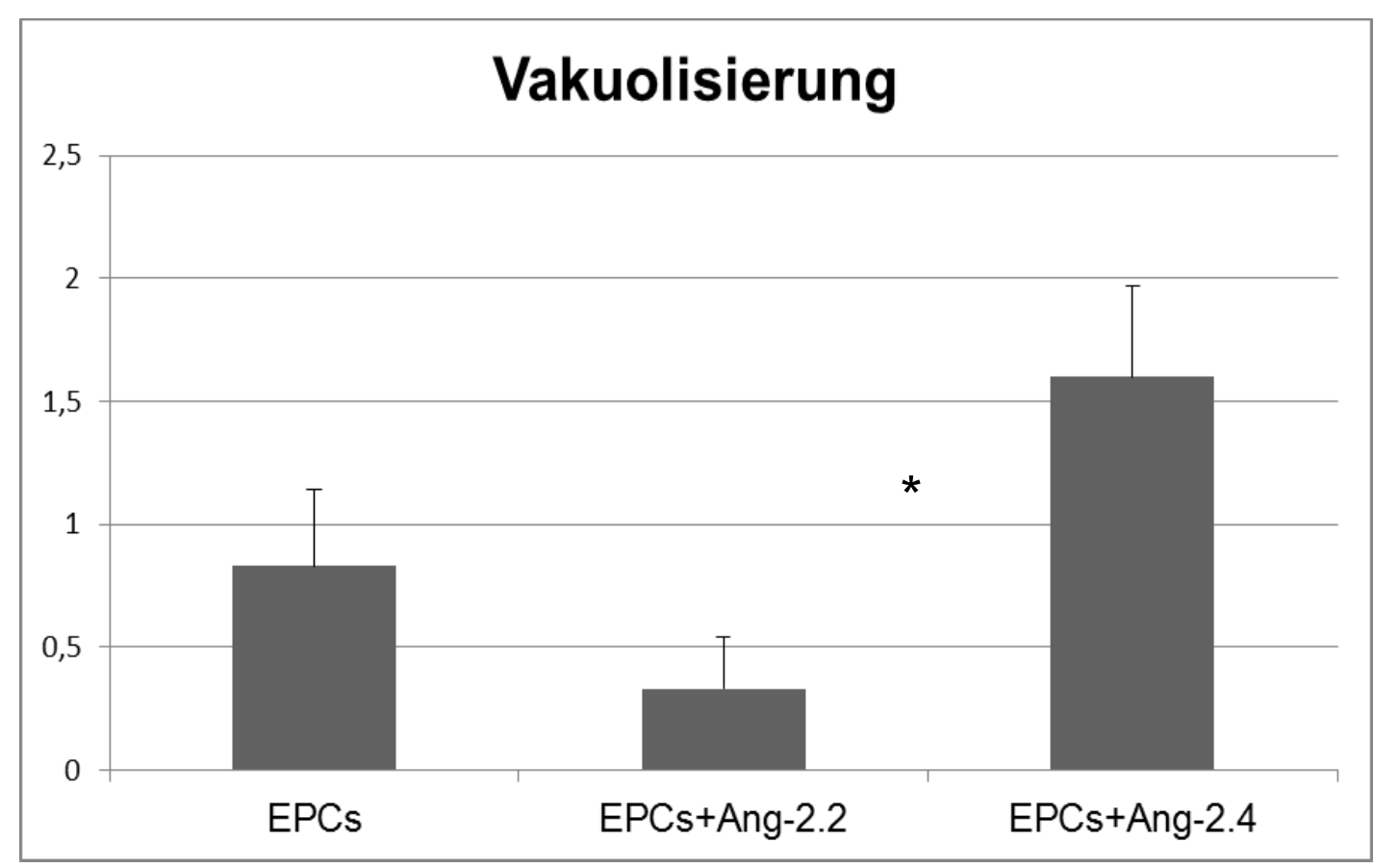

Abbildung 5: Vakuolisierung; Ergebnisse als Mittelwerte und SEM, *: $p<0,05$; Es zeigt sich eine signifikant geringere Vakuolisierung in der Gruppe EPCs+Ang2.2 (Gruppe 4) verglichen mit der Gruppe EPCs+Ang-2.4 (Gruppe 5). 


\begin{tabular}{|c|c|c|c|}
\hline & $\begin{array}{l}0,5 \times 10^{6} \text { EPCs } \\
\text { (Gruppe } 3 \text { ) }\end{array}$ & $\begin{array}{l}0,5 \times 10^{6} \text { EPCs + } \\
\text { Ang-2.2 } \\
\text { (Gruppe 4) }\end{array}$ & $\begin{array}{l}0,5 \times 10^{6} \text { EPCs + } \\
\text { Ang-2.4 } \\
\text { (Gruppe 5) }\end{array}$ \\
\hline \multicolumn{4}{|l|}{ Versuchstier } \\
\hline 1 & 1 & 1 & 1 \\
\hline 2 & 1 & 0 & 1 \\
\hline 3 & 2 & 1 & 3 \\
\hline 4 & 2 & 0 & 1 \\
\hline 5 & 2 & 1 & 2 \\
\hline 6 & 2 & 0 & 1 \\
\hline
\end{tabular}

Tabelle 6: Bürstensaumverlust in den Graden 0-3

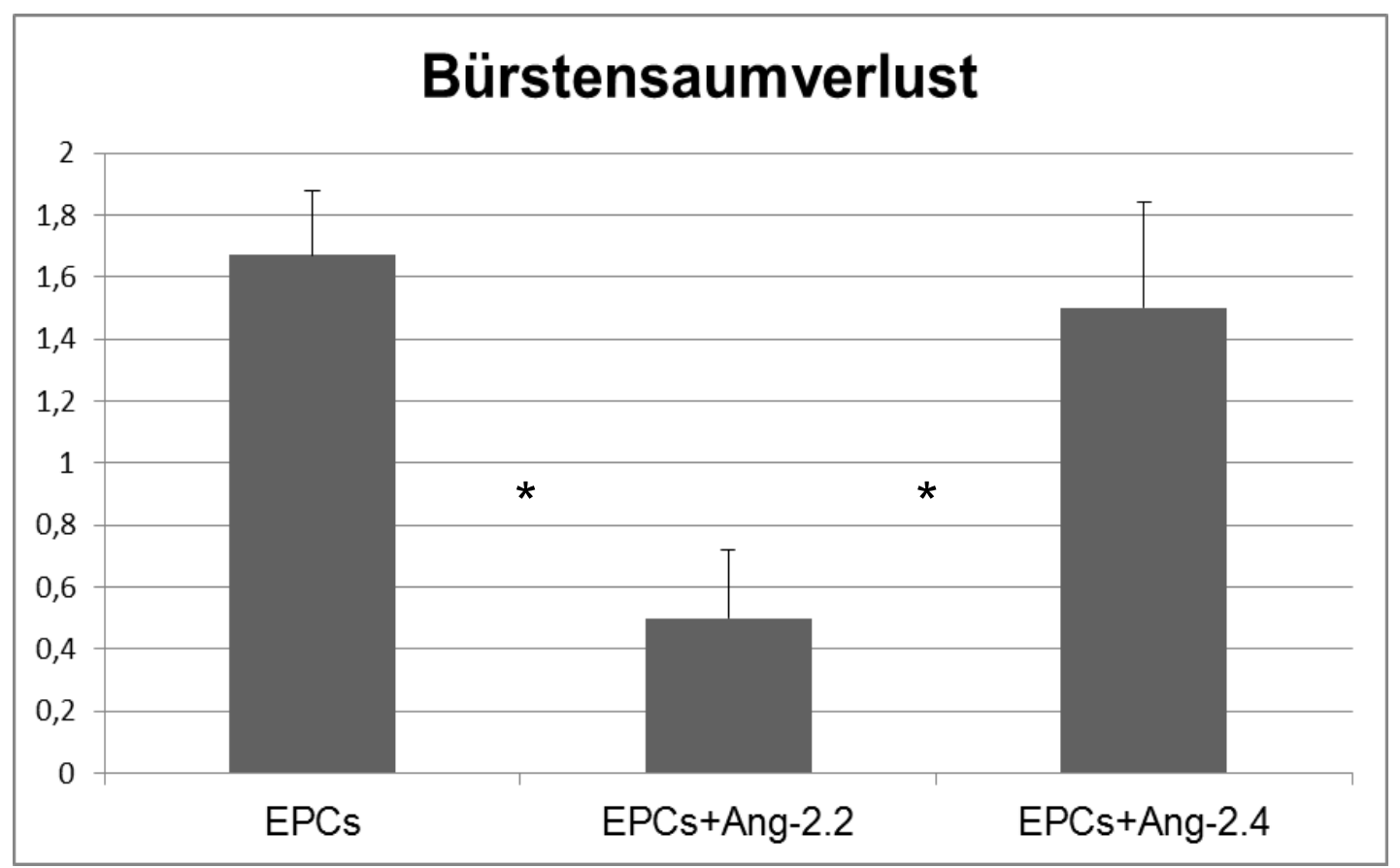

Abbildung 6: Bürstensaumverlust; Ergebnisse als Mittelwerte und SEM, *: $p<0,05$; Es zeigt sich ein signifikant geringerer Bürstensaumverlust in der Gruppe EPCs+Ang-2.2 (Gruppe 4) im Vergleich zu den Gruppen EPCs (Gruppe 3) und EPCs+Ang-2.4 (Gruppe 5). 


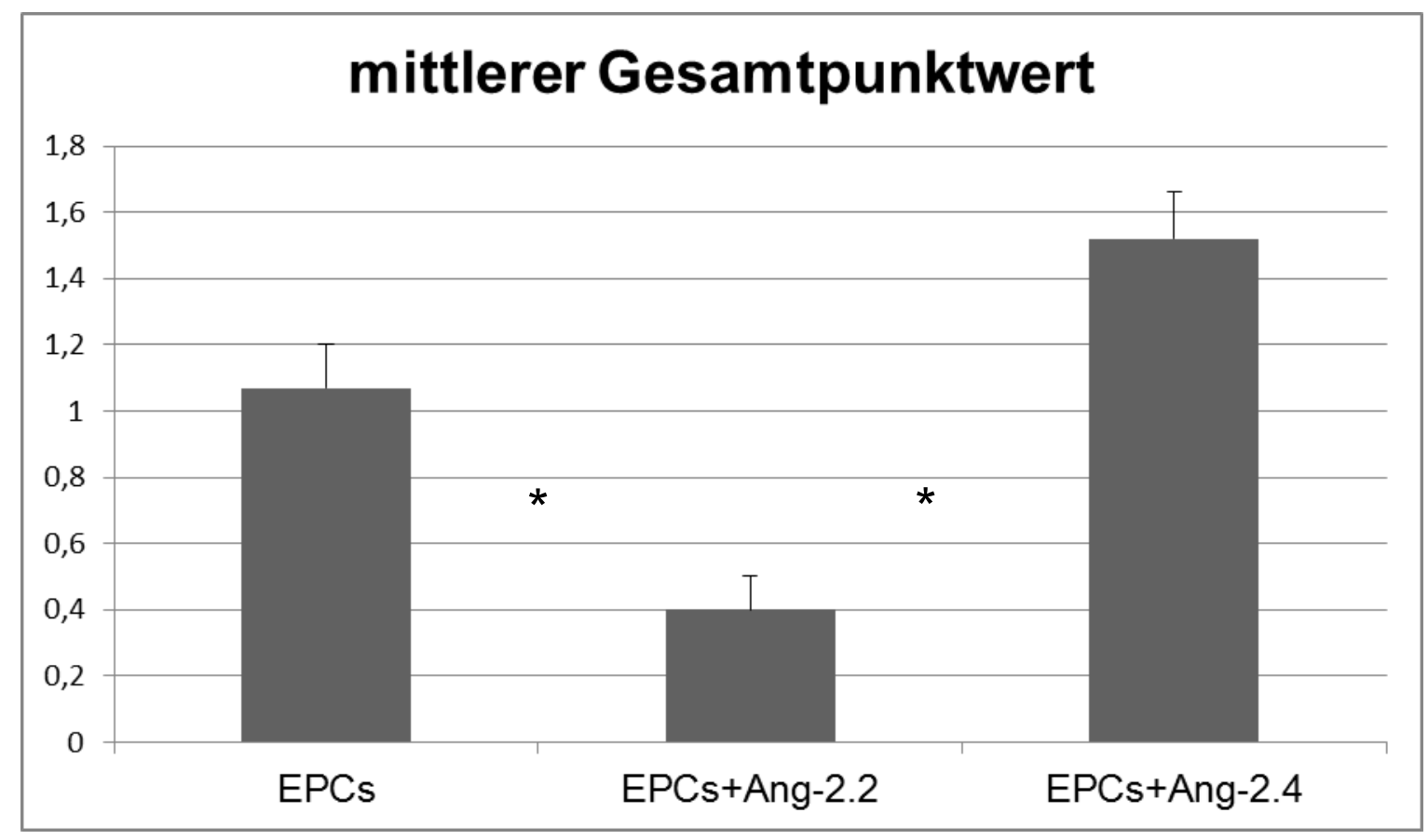

Abbildung 7: mittlerer Gesamtpunktwert der Zellschäden als Mittelwert und SEM, *: p<0,05; In der Gruppe EPCs+Ang-2.2 (Gruppe 4) waren die ausgeprägten Zellschäden in den gesamten Parametern gegenüber der Gruppe EPCs (Gruppe 3) und der Gruppe EPCs+Ang-2.4 (Gruppe 5) verringert und führten somit zu einem signifikant kleineren mittleren Gesamtpunktpunkt. Dieser war in der Gruppe EPCs+Ang-2.4 (Gruppe 5) auch signifikant zur Gruppe EPCs (Gruppe 3) erhöht.

\subsection{Immunfluoreszenzhistologie}

Die immunfluoreszzenzhistologische Untersuchung ergab keine Unterschiede in den intrarenalen Infiltraten durch cell tracker+/c-Kit+-Zellen. Prinzipiell waren in allen zellinjizierten Tieren nur sehr wenige Zellen im jeweiligen Organ nachweisbar. Diese Beobachtung überraschte nicht, waren doch vergleichbare Resultate bereits aus früheren Studien bekannt. Daher wurde auf eine graphische Darstellung dieser Befunde verzichtet. 


\section{Diskussion}

Mit Hilfe der vorliegenden Arbeit sollte eine neue Methode der EPCVorbehandlung untersucht werden, die das nephroprotektive Potential von EPCs im Rahmen eines ischämischen ANVs steigern könnte. Vor dem Hintergrund der bekannten vasomodulierenden Wirkungen von Angiopoetin-2 bestand die Hoffnung, dass sich das nephroprotektive Potential von EPCs beim ischämischen ANV mit Hilfe der Substanz steigern ließe. Angiopoetin-2 entfaltet prinzipiell dosisabhängige, vielgestaltige Wirkungen auf den endothelialen Zellverband. Diese Effekte werden später genauer beschrieben. Alle vorgestellten Experimente erfolgten im Mausmodell. Hierbei wurden in jeder Versuchsreihe die linken Nierengefäße für 40 Minuten abgeklemmt, um ein ANV zu simulieren. Gleichzeitig wurde die kontralaterale Niere mittels Nephrektomie entfernt. Unmittelbar nach dem Lösen der Gefäßklemme erfolgte die Injektion der unbehandelten oder vorbehandelten EPCs. Die Ergebnisse der Versuchsreihen sind im Folgenden dargestellt:

- $\quad$ Die Applikation von 500.000 nicht vorbehandelten EPCs führte nach einer 40-minütigen renalen Ischämie zu keiner signifikanten Verbesserung der postischämischen Nierenfunktion zellbehandelter Mäuse. Dabei wurde ein Vergleich mit Tieren vorgenommen, die lediglich Kochsalz erhalten hatten.

Die systemische Injektion von 500.000 mit Angiopoetin-2 in einer Konzentration von $400 \mathrm{ng} / \mathrm{ml}$ vorbehandelten EPCs führte zu einer signifikanten Verbesserung der Nierenfunktion nach einer 40-minütigen Ischämie.

Bei Erhöhung der Angiopoetin-2-Konzentration auf $800 \mathrm{ng} / \mathrm{ml}$ resultierte nach der EPC-Injektion eine signifikante Verschlechterung der Nierenfunktion

Diese merklichen Unterschiede der Ang-2-Wirkung deuten auf einen dosisabhängigen Wirkmechanismus des Proteins hin. Ang-2 kann somit in einer bestimmten Konzentration, hier $400 \mathrm{ng} / \mathrm{ml}$, nephroprotektiv wirken, es kann aber auch kontraproduktiv wirken und die Nierenfunktion deutlich verschlechtern, hier in der Konzentration von $800 \mathrm{ng} / \mathrm{ml}$. Daher ist bei einer 
Therapie mit Ang-2-vorbehandelten EPCs beim akuten ischämischen Nierenversagen ein bestimmtes Konzentrationsverhältnis notwendig und stets Vorsicht geboten. Mit Ang-2 wurde eine Substanz gewählt, die im Blutgefäßumbau sowie im Rahmen von Entzündungsprozessen eine tragende Rolle spielt. Ang-2 wurde in den letzten Jahren hinsichtlich seiner Wirkungsweise und seiner Funktion bei bestimmten Erkrankungen zunehmend genauer untersucht.

So ist bekannt, dass der Serumspiegel von Ang-2 bei septischen Patienten mit vaskulärem leakage erhöht ist. HDIL 2 (high dose interleukin 2) wird in der Tumortherapie eingesetzt und führt zum vascular leak syndrome (VLS). Eine Inhibiton von Ang-2, so wurde von den Autoren gemutmaßt, könnte das HDIL 2-Therapie-assoziierte VLS möglicherweise abmildern. Der verantwortliche Mechanismus bestünde möglicherweise in der kompetetiven Hemmung von Ang-1 an den Tie-2 Rezeptor (Gallagher et al. 2007).

Des Weiteren ergaben Untersuchungen an der Retina, dass Ang-2 auch hier eine wichtige Rolle in der Hypoxie-induzierten retinalen Neovaskulisation spielt. In der pathologischen Angiogenese konnte eine erhöhte MMP (MatrixMetalloproteinase)-Aktivität bewiesen werden. Die verminderte Expression von Ang-2 in der Retina reduziert die angiogene Antwort der retinalen Gefäße auf Hypoxie, verbunden mit einer verminderten MMP-Aktivität im Prozess der Angiogenese (Feng et al. 2008).

Weitere Untersuchungen bezüglich des Angiopoetins-2 zeigten, dass dessen Abwesenheit nicht vor einem murinen ANV bei einer LPS (Lipopolysaccharide)Behandlung schützt (Kurniati et al. 2013).

Zirkulierendes Ang-2 konnte zudem als ein starker und unabhängiger Indikator für die Sterblichkeit von Patienten mit einem dialysepflichtigen ANV auf der Intensivstation identifiziert werden. Die Ang-2-Konzentrationen waren bei Nichtüberlebenden erhöht (Kümpers et al. 2010). Die Autoren konnten in vorangegangenen Untersuchungen auch zeigen, dass Ang-2 bei der ANCAassoziierten Vaskulitis (AAV) mit Nierenbeteiligung, verglichen mit einer Kontrollgruppe sowie mit Patienten in Remission, signifikant erhöht war. Zirkulierendes Ang-2 war erhöht und korrelierte mit dem BVAS sowie der Anzahl zirkulierender endothelialer Zellen. Dies deutet darauf hin, dass Ang-2 
ein potentieller Mediator des Zell-Zell-Kontakts bei AAV sein könnte (Kümpers et al. 2009).

Die Wirkungsmechanismen von Ang-2 bzw. die Interaktion mit seinem Rezeptor werden immer noch intensiv analysiert. So konnten Yuan et al. 2009 zeigen, dass Ang-2 sowohl als Agonist wie auch als Antagonist auf Tie-2 im Endothel wirken kann. Sie fanden heraus, dass bei Fehlen von Ang-1 agonistische Wirkungen von Ang-2 an Tie-2 entfaltet werden. Ist Ang-1 hingegen anwesend, wirkt Ang-2 dosisabhängig als Antagonist. Exogenes Ang-2 aktiviert Tie-2 und dessen Signalweg in ECs jedoch mit geringerer Potenz und Affinität als exogenes Ang-1. Die Endothelzellen können jedoch Ang-2 selbst produzieren, Ang-1 hingegen nicht. Dieses endogene Ang-2 erhält die Tie-2-Aktivitäten aufrecht. Bei gleichzeitiger Stimulation von Ang-1 und Ang-2 auf Endothelzellen inhibiert das Ang-2 jedoch dosisabhängig die Phosphorylierung des Tie-2Rezeptors durch Ang-1. Die Autoren schlossen aus diesen Untersuchungen, dass Ang-2 sowohl als Agonist wie auch als Antagonist wirkt. Obwohl die Agonistenwirkung schwächer als die des Angiopoetins-1 ist, hält Ang-2 das Level der Tie-2-Aktivierung, welches für zahlreiche Endothelzellfunktionen kritisch ist, aufrecht bzw. stabil (Yuan et al. 2009).

Weiterhin konnte gezeigt werden, dass die Tie-2-Bindung durch Ang-2 im Gegensatz zur Bindung durch Ang-1 nicht durch Tie-1 inhibiert wird. Die Bindung an Tie-2 wird sowohl bei Ang-1 als auch bei Ang-2 durch Tie-1 kontrolliert (Hansen et al. 2010).

Zudem belegen neuere Untersuchungen die kontextabhängige Wirkung von Ang-2 auf Endothelzellen (ECs), wobei der molekulare Mechanismus weiterhin ungenau verstanden ist. So konnte gezeigt werden, dass Ang-2 selbst dann auf ECs wirken kann, wenn diese keine Tie-2-Rezeptoren haben. Solche Tie-2negativen ECs existieren an den distalen Ausläufern proliferierender Kapillaren. Diese Zellen exprimieren jedoch reichlich Integrine auf ihrer Oberfläche. Über diese Signalkaskade kann Ang-2 Angiogenese induzieren (Felcht et al. 2012).

Die Wirkung von Ang-2 im Rahmen einer Revaskularisierungstherapie konnte zuletzt tierexperimetell an postischämischen Hintergliedmaßen gezeigt werden. Hier resultierte die Überexpression des partiellen Tie-2-Agonisten Ang-2 in einer gesteigerten und verbesserten Perfusion sowie in einer rascheren 
Kollateralgefäßbildung. Dies konnte für Ang-1 nicht gezeigt werden (Lekas et al. 2012).

Anhand unserer Untersuchungen konnte nun gezeigt werden, dass Angiopoetin-2 dosisabhängig die nephroprotektive Wirkung der EPCs sowohl verstärken als auch wesentlich verschlechtern kann. Diese dosisabhängige Wirkung des Ang-2 wurde, wie bereits oben erwähnt, auch bei anderen Untersuchungen bereits erforscht und nachgewiesen. Besonderes Augenmerk beim akuten ischämischen Nierenversagen gilt den Nierentubuli und den diese umgebenden Gefäßen. Diese stehen in direktem Kontakt mit den Tubuluszellen und werden durch die Ischämie besonders geschädigt. Die verminderte Durchblutung der Niere führt zu funktionellen Einbußen und später auch strukturellen Veränderungen nahezu aller Zellen des Organs. Aus der Minderdurchblutung resultierend, kommt es zunächst zum Anschwellen der Tubulusepithelzellen. Dadurch werden die sie umgebenden Blutgefäße erheblich eingeengt. Durch die Minderperfusion dieser Nierenbereiche liegt ein schlechteres Regenerationspotential sowohl der Tubuluszellen als auch des Gefäßendothels vor. Prinzipiell haben diese Zelltypen ein hohes Regenerationspotential, welches mit Hilfe der EPCs im Rahmen des ANVs bedeutend gesteigert werden kann. Die Wirksamkeit der EPCs konnte beim ANV im Mausmodell bisher mehrfach belegt werden. So konnten Patschan et al. in den von innen veröffentlichten Arbeiten 2006 zeigen, dass sich EPCs nach einseitiger renaler Ischämie bereits nach drei Stunden in den Milzen der betroffenen Versuchstiere ansammeln (Patschan et al. 2006a). In weiteren Untersuchungen konnte der Autor zeigen, dass es zu einer deutlichen Anreicherung von EPC-Infiltraten im medullären Teil der postischämischen Niere kommt, wenn diese einer zweimaligen im Abstand von sieben Tagen 25minütigen Ischämiebehandlung unterzogen wurden. Nach Isolation dieser Zellen und ihrer Applikation in Empfängermäuse nach beidseitiger, renaler Ischämie zeigte sich kein akutes Nierenversagen (Patschan et al. 2006a). Spätere Untersuchungen konnten reproduzierbar zeigen, dass EPCs bei unterschiedlichen Schweregraden des ANVs nephroprotektiv wirken. Die schützende Wirkung ist jedoch bei einer Ischämiedauer von mehr als 35 Minuten nicht mehr vorhanden. Die therapeutische Wirksamkeit solcher konstanten EPC-Mengen nimmt folglich mit zunehmender Ischämiedauer ab (Patschan et al. 2010). 
Aufgrund dieser Ergebnisse ist es wünschenswert, Therapiekonzepte zu finden, mit deren Hilfe man die nephroprotektive Wirkung der EPCs steigern kann. Eine Möglichkeit für die Steigerung dieser Wirkung besteht in der Vorbehandlung der EPCs mit der Substanz 8-pCPT-2'-O-Me-cAMP (EPAC 1-Ac). Diese Vorbehandlung bewirkt die vermehrte Expression von beta 1-Integrinen auf der EPC-Oberfläche. Mit Hilfe dieser Zelladhäsionsmoleküle findet ein verstärktes homing von Leukozyten in das entzündete Gewebe statt. Durch diese aktivierten beta-1-Integrine wurde die antiischämische Potenz der injizierten EPCs erhöht und es wurden diese vermehrt in den betroffenen Organen nachgewiesen (Patschan et al. 2010). Die Vorbehandlung mit dem Hormon Melatonin führt ebenfalls zu einer Verbesserung des nephroprotektiven Effekts der EPCs. Hierbei zeigte sich, dass mit Melatonin vorbehandelte EPCs mehr VEGF freisetzen als nicht vorbehandelte Zellen (Patschan et al. 2012).

Die aktuelle Arbeit ergab zwei wesentliche Ergebnisse: (I) Es wurde mit Angiopoetin-2 ein weiterer Agonist muriner EPCs beim ischämischen ANV identifiziert. (II) Es ist allerdings zu bemerken, dass der Einsatz von potentiellen EPC-Aktivatoren beim ANV keinesfalls unkritisch erfolgen darf. Unter bestimmten Bedingungen (in diesem Fall Intensivierung der Inkubationskonzentration) wird mit einer Zellvorbehandlung genau der gegenteilige Effekt erzielt: es kommt zu einer Verschlechterung der Nierenfunktion postischämischer Tiere.

Weitere Untersuchungen sind notwendig, um ein "optimales“ Präkonditionierungsprotokoll für EPCs beim ANV zu finden. Zudem sind die Mechanismen, über die Ang-2-behandelte EPCs die postischämische Nierenfunktion verschlechtern, bislang noch vollständig unbekannt. 


\section{Zusammenfassung}

Zielsetzung dieser Arbeit war die Etablierung einer neuen Strategie, die den nephroprotektiven Effekt der EPCs bei der verlängerten Ischämiedauer von 40 Minuten beim ANV verbessert. Der Substanz Angiopoetin-2 wurde hierbei eine potentiell verstärkende Wirkung zugeschrieben und im Rahmen dieser Untersuchungen wurden die EPCs mit verschiedenen Konzentrationen an Ang2 vorbehandelt. Bisherige Untersuchungen ergaben bereits eine verstärkende Wirkung der EPCs bei einer Vorbehandlung dieser mit EPAC 1-Ac (Patschan et al. 2010) und Melatonin (Patschan et al. 2012).

Die Untersuchungen fanden im Mausmodell statt. Hierbei wurde die linke Niere der Tiere für 40 Minuten abgeklemmt. Nach der stattgefundenen Ischämiesimulation wurden die entsprechenden Lösungen in das Gefäß der kontralateralen Niere injiziert und diese anschließend entfernt. Somit wurde sichergestellt, dass die nun folgende Nierentätigkeit nur noch von der zuvor geschädigten Niere übernommen werden konnte. Als Zellmenge dienten 500.000 EPCs, die zuvor ausgezählt wurden. Die anschließende Inkubation mit der Testsubstanz Angiopoetin-2 erfolgte in zwei unterschiedlichen Konzentrationen: $400 \mathrm{ng} / \mathrm{ml}$ und $800 \mathrm{ng} / \mathrm{ml}$.

Die Aussagen über die Wirksamkeit der jeweiligen Behandlung erfolgte über die Kreatininwertbestimmung des Serums 48 Stunden post OP sowie über histologische und immunfloureszenzhistologische Schnitte der geschädigten, zuvor entnommenen Niere.

Es wurden verschiedene Gruppen untersucht. Zunächst wurde den Kontrolltieren lediglich physiologische Kochsalzlösung injiziert. Diese Gruppe diente als Referenzgruppe. Darauffolgend wurde die Wirksamkeit von 500.000 unbehandelten EPCs untersucht, bevor diese in den beiden folgenden Gruppen in den Konzentrationen von $400 \mathrm{ng} / \mathrm{ml}$ bzw. $800 \mathrm{ng} / \mathrm{ml}$ mit Angiopoetin-2 vorbehandelt wurden.

Es zeigte sich, dass die alleinige Injektion von 500.000 nicht vorbehandelter EPCs nicht zu einer signifikanten Nephroprotektion führt. Die Vorbehandlung der EPCs mit Angiopoetin-2 in der Konzentration von $400 \mathrm{ng} / \mathrm{ml}$ führte zu einer signifikanten Nephroprotektion. Das war anhand der signifikant gesunkenen 
Kreatininwerte sowie histologisch an weniger Zellschäden in den verschiedenen Parametern Detritus, Kernverlust, Bürstensaumverlust, Vakuolisierung und Epithelabflachung ersichtlich.

Wurde die Konzentration des Ang-2 auf $800 \mathrm{ng} / \mathrm{ml}$ vor Inkubation der EPCs erhöht, war keine Nephroprotetktion mehr vorhanden. Es kam vielmehr zu einer deutlich schlechteren Nierenfunktion. Sehr hohe Serumkreatininwerte sowie histologisch große Schäden in den oben genannten Parametern der untersuchten Gewebeschnitte bestätigten die starke Nierenschädigung.

Um die Vorbehandlung der EPCs mit Ang-2 als potentiell verstärkende Substanz für die nephroprotektive Wirkung der EPCs zu etablieren, sind weitere Untersuchungen hinsichtlich des Wirkmechanismus des Ang-2 zu identifizieren. Dies ist aufgrund der sehr unterschiedlichen, konzentrationsabhängigen Wirkungen in unseren Versuchen notwendig. 


\section{Anhang}

\begin{tabular}{|c|c|c|c|}
\hline Stoff & $\begin{array}{l}\text { Hersteller- } \\
\text { firma }\end{array}$ & $\begin{array}{l}\text { Katalog- } \\
\text { nummer }\end{array}$ & Verwendung \\
\hline $\begin{array}{l}\text { Ketamine/ } \\
\text { Xylazine }\end{array}$ & $\begin{array}{l}\text { SIGMA- } \\
\text { ALDRICH }\end{array}$ & $\mathrm{K}-113$ & Anästhesie \\
\hline Heparin & RATIOPHARM & N21086.21.Z04 & $\begin{array}{l}\text { Blutgerinnungshemmung } \\
\text { bei Zellisolation }\end{array}$ \\
\hline EBM-2 Medium & LONZA & CC-3156 & Verschiedenes \\
\hline Biocoll & $\begin{array}{l}\text { BIOCHROM } \\
\text { AG }\end{array}$ & L-6115 & $\begin{array}{l}\text { Dichtetrennung der EPCs } \\
\text { aus Vollblut und Milz }\end{array}$ \\
\hline Fibronectin & $\begin{array}{l}\text { SIGMA- } \\
\text { ALDRICH }\end{array}$ & F0895 - 1MG & Zellkultivierung \\
\hline $\begin{array}{l}\text { Recombinant } \\
\text { Human } \\
\text { Angiopoetin-2 }\end{array}$ & Biocat & $4922-10$ & Zellstimulierung \\
\hline Formalin & MERCK & 1039992500 & Organfixierung \\
\hline Phosphatpuffer & GIBCO & $10010-015$ & $\begin{array}{l}\text { Verdünnung und } \\
\text { Waschung }\end{array}$ \\
\hline Tissue Tek & SAKURA OCT & 4583 & $\begin{array}{l}\text { Organfixierung für } \\
\text { Kryoschnitte }\end{array}$ \\
\hline Eiweißglycerin & ROTH & P049.1 & $\begin{array}{l}\text { Objektträgervorbehandlung } \\
\text { für Kryoschnitte }\end{array}$ \\
\hline $\begin{array}{l}\text { Bovine Serum } \\
\text { Albumin }\end{array}$ & PAA & K41-001 & Kryoschnittvorbehandlung \\
\hline $\begin{array}{l}\text { FITC anti- } \\
\text { mouse } \\
\text { CD117/c-kit }\end{array}$ & $\mathrm{BD}$ & 553354 & $\begin{array}{l}\text { Antikörper zur EPC- } \\
\text { Markierung in den } \\
\text { Kryoschnitten }\end{array}$ \\
\hline $\begin{array}{l}\text { Flourescence } \\
\text { Mounting } \\
\text { Medium }\end{array}$ & DAKO & S3023 & Kryoschnitteindeckung \\
\hline Creatinin PAP & $\begin{array}{l}\text { TECHNIK } \\
\text { EBERHARD } \\
\text { LEHMANN }\end{array}$ & LT-CR 0101 & $\begin{array}{l}\text { Bestimmung des } \\
\text { Serumkreatinins }\end{array}$ \\
\hline Cell Tracker ${ }^{\circledR}$ & INVITROGEN & C700 & Zellmarkierung \\
\hline DAPI-Lösuna & MiBi-Tec & & \\
\hline
\end{tabular}

Tabelle 7: Liste der verwendeten chemischen Stoffe mit Angabe der Firma und

Katalognummer 


\begin{tabular}{|c|c|c|}
\hline Gerät & Firma & Verwendung \\
\hline Schere klein (14568-12) & FINE SCIENCE TOOLS & Operation \\
\hline Schere groß (14502-14) & FINE SCIENCE TOOLS & Operation \\
\hline Pinzette groß (11-008-15) & FINE SCIENCE TOOLS & Operation \\
\hline $\begin{array}{l}\text { Pinzette klein Stahl 10cm } \\
0,8 \mathrm{~mm}(11050-10)\end{array}$ & FINE SCIENCE TOOLS & Operation \\
\hline $\begin{array}{l}\text { Pinzette chirurgisch slim } \\
(11023-14)\end{array}$ & FINE SCIENCE TOOLS & Operation \\
\hline $\begin{array}{l}\text { Nadelhalter Matthieu } 14 \mathrm{~cm} \\
(12510-14)\end{array}$ & FINE SCIENCE TOOLS & $\begin{array}{l}\text { Operation } \\
\text { (Wundversorgung/ } \\
\text { Naht) }\end{array}$ \\
\hline Clipapplikator (18057-14) & FINE SCIENCE TOOLS & $\begin{array}{l}\text { Operation (Applikation } \\
\text { der Nierenklemme } \\
\text { (Clip)) }\end{array}$ \\
\hline Clip 6mm (18055-03) & FINE SCIENCE TOOLS & $\begin{array}{l}\text { Operation } \\
\text { (Nierenabklemmung) }\end{array}$ \\
\hline Instrumentenbox (20311-21) & FINE SCIENCE TOOLS & $\begin{array}{l}\text { Instrumentenaufbe- } \\
\text { wahrung }\end{array}$ \\
\hline Faden (Nr. 100 6830) & Henry Schein & $\begin{array}{l}\text { Operation } \\
\text { (Nahtmaterial zur } \\
\text { Wundversorung) }\end{array}$ \\
\hline $\begin{array}{l}\text { Insulinspritze, Safety Glide } \\
\text { (Nr. 305930) }\end{array}$ & BD & $\begin{array}{l}\text { Operation (Applikation } \\
\text { der jeweiligen Stoffe in } \\
\text { das Nierengefäß) }\end{array}$ \\
\hline $\begin{array}{l}\text { Spectrophotometer (UV-120- } \\
01 \text { ) }\end{array}$ & SCHIMADZU & Kreatinwertbestimmung \\
\hline Pipette $(0,5-10 \mu \mathrm{l})$ & EPPENDORF & Laborarbeiten \\
\hline $\begin{array}{l}\text { Pipettierspitzen für } 0,5-10 \mu \mathrm{l} \\
\text { Pipette }\end{array}$ & EPPENDORF & Laborarbeiten \\
\hline Pipette $(10-100 \mu \mathrm{l})$ & EPPENDORF & Laborarbeiten \\
\hline $\begin{array}{l}\text { Pipettierspitzen für } 10-100 \\
\mu l \text { Pipette }\end{array}$ & EPPENDORF & Laborarbeiten \\
\hline Pipette $(100-1000 \mu l)$ & EPPENDORF & Laborarbeiten \\
\hline $\begin{array}{l}\text { Pipettierspitzen für } 100- \\
1000 \mu \text { l Pipette }\end{array}$ & EPPENDORF & Laborarbeiten \\
\hline Zentrifuge (G5-6R) & BECKMANN & Zellisolation \\
\hline Photometerreader & TECA SPECTRA & ELISA Auswertung \\
\hline $\begin{array}{l}\text { Tissue Block Dispenser PAG } \\
12\end{array}$ & $\begin{array}{l}\text { MEDITE } \\
\text { MEDIZINTECHNIK }\end{array}$ & Ausgießstation \\
\hline Gewebeinfiltrationsautomat & LEICA TP 1020 & $\begin{array}{l}\text { Formalinauswaschung } \\
\text { der Dünnschnitte }\end{array}$ \\
\hline Gefriermikrotom & LEICA, Jung CM 3000 & Dünnschnittherstellung \\
\hline Autocut Microtom & LEICA Reichert-Jung 2040 & Dünnschnittherstellung \\
\hline Floureszenzmikroskop & ZEISS, Axiovert S100 TV & Mikroskopie \\
\hline
\end{tabular}

Tabelle 8: Liste der verwendeten chirurgischen Instrumente und Geräte 


\section{Abkürzungsverzeichnis}

\begin{tabular}{|c|c|}
\hline Ang & Angiopoetin \\
\hline ANCA & anti-neutrophil cytoplasmic antibodies \\
\hline ANV & Akutes Nierenversagen \\
\hline BSA & bovine serum albumin \\
\hline BVAS & Birmingham Vasculitis Activity Score \\
\hline cAMP & zyklisches Adenosismonophosphat \\
\hline CD & cluster of differentiation \\
\hline CFU-EC & colony forming unit endothelial cell \\
\hline DAPI & 4',6-Diamidin-2-phenylindol \\
\hline EBM & endothelial basal medium \\
\hline EC & endothelial cell \\
\hline eEOC & early endothelial outgrowth cell \\
\hline EPAC & exchange protein directly activated by $c A M P$ \\
\hline EPAC 1-Ac & EPAC 1 activator \\
\hline EPC & endothelial progenitor cell \\
\hline FITC & Flouresceinisothiocyanat \\
\hline Flk & fetal liver kinase \\
\hline G-CSF & granulocyte colony-stimulating factor \\
\hline GM-CSF & granulocyte macrophage colony-stimulating factor \\
\hline HDIL & high dose interleukin \\
\hline HGF & hepatocyte growth factor \\
\hline HPC & hematopoietic progenitor cells \\
\hline
\end{tabular}




\begin{tabular}{|c|c|}
\hline HSC & hematopoietic stem cell \\
\hline HUVEC & human umbilical vein endothelial cell \\
\hline IL & Interleukin \\
\hline KDR & kinase insert domain receptor \\
\hline IEOC & late endothelial outgrowth cell \\
\hline LPS & Lipopolysaccharide \\
\hline MMP & Matrix-Metalloproteinase \\
\hline MNC & mononukleäre Zellfraktion \\
\hline MSU & monosodium urate \\
\hline MT & Melatonin-Rezeptor \\
\hline PAS & periodic acid-Schiff \\
\hline PBS & phosphate buffered saline \\
\hline PECAM & platelet endothelial cell adhesion molecule \\
\hline SD & standard deviation \\
\hline SEM & standard error of the mean \\
\hline Tie & tyrosine kinase with $\lg G$ and EGF-like repeats \\
\hline TNF & tumor necrosis factor \\
\hline VEGF & vascular endothelial growth factor \\
\hline VLS & vascular leak syndrome \\
\hline vWF & Von-Willebrand-Factor \\
\hline WPB & Weibel-Palade body \\
\hline
\end{tabular}




\section{Literaturverzeichnis}

Adams V, Lenk K, Linke A, Lenz D, Erbs S, Sandri M, Tarnok A, Gielen S, Emmrich F, Schuler $G$ (2004): Increase of circulating endothelial progenitor cells in patients with coronary artery disease after exercise-induced ischemia. Arterioscler Thromb Vasc Biol 24, 684-690

Asahara T, Murohara T, Sullivan A, Silver M, van der Zee R, Li T, Witzenbichler B, Schatteman G, Isner JM (1997): Isolation of putative progenitor endothelial cells for angiogenesis. Science $\underline{275}, 964-967$

Asahara T, Masuda H, Takahashi T, Kalka C, Pastore C, Silver M, Kearne M, Magner M, Isner JM (1999): Bone marrow origin of endothelial progenitor cells responsible for postnatal vasculogenesis in physiological and pathological neovascularization. Circ Res $\underline{85}, 221-228$

Bahte SK, Bertram A, Burkhardt O, Martens-Lobenhoffer J, Goedecke V, BodeBöger SM, Hiss M, Kielstein JT (2010): Therapeutic serum concentrations of daptomycin after intraperitoneal administration in a patient with peritoneal dialysis-associated peritonitis. J Antimicrob Chemother $\underline{65}, 1312-1314$

Bailey AS, Jiang S, Afentoulis M, Baumann Cl, Schroeder DA, Olson SB, Wong $\mathrm{MH}$, Fleming WH (2004): Transplanted adult hematopoietic stems cells differentiate into functional endothelial cells. Blood 103, 13-19

Baldwin HS, Shen HM, Yan HC, DeLisser HM, Chung A, Mickanin C, Trask T, Kirschbaum NE, Newman PJ, Albelda SM (1994): Platelet endothelial cell adhesion molecule-1 (PECAM-1/CD31): alternatively spliced, functionally distinct isoforms expressed during mammalian cardiovascular development. Development $\underline{120}, 2539-2553$

Brandenburger T, Bajorat T: Fallbuch Biochemie - 80 Fälle aktiv bearbeiten. Georg Thieme Verlag KG, Stuttgart 2006, 250

Brodsky SV, Yamamoto T, Tada T, Kim B, Chen J, Kajiya F, Goligorsky MS (2002): Endothelial dysfunction in ischemic acute renal failure: rescue by transplanted endothelial cells. Am J Physiol Renal Physiol 282, F1140-1149 
Carlson TR, Feng Y, Maisonpierre PC, Mrksich M, Morla AO (2001): Direct cell adhesion to the angiopoietins mediated by integrins. J Biol Chem $\underline{276}$, 2651626525

Case J, Mead LE, Bessler WK, Prater D, White HA, Saadatzadeh MR, Bhavsar JR, Yoder MC, Haneline LS, Ingram DA (2007): Human CD34+AC133+VEGFR$2+$ cells are not endothelial progenitor cells but distinct, primitive hematopoietic progenitors. Exp Hematol $\underline{35}, 1109-1118$

Centers for Disease Control and Prevention (2008): Hospitalization Discharge Diagnoses for Kidney Disease - United States, 1980-2005. MMWR $\underline{57}$, 309-312

Davis S, Aldrich TH, Jones PF, Acheson A, Compton DL, Jain V, Ryan TE, Bruno J, Radziejewski C, Maisonpierre PC (1996): Isolation of angiopoietin-1, a ligand for the TIE2 receptor, by secretion-trap expression cloning. Cell $\underline{87}$, 1161-1169

Davis S, Papadopoulos N, Aldrich TH, Maisonpierre PC, Huang T, Kovac L, Xu A, Leidich R, Radziejewska E, Rafique A (2003): Angiopoietins have distinct modular domains essential for receptor binding, dimerization and superclustering. Nat Struct Biol 10, 38-44

de Groot K, Bahlmann FH, Sowa J, Koenig J, Menne J, Haller H, Fliser D (2004): Uremia causes endothelial progenitor cell deficiency. Kidney Int $\underline{66}$, 641-646

Dumont DJ, Yamaguchi TP, Conlon RA, Rossant J, Breitman ML (1992): tek, a novel tyrosine kinase gene located on mouse chromosome 4, is expressed in endothelial cells and their presumptive precursors. Oncogene $\underline{7}, 1471-1480$

Dumont DJ, Gradwohl G, Fong GH, Puri MC, Gertsenstein M, Auerbach A, Breitman ML (1994): Dominant-negative and targeted null mutations in the endothelial receptor tyrosine kinase, tek, reveal a critical role in vasculogenesis of the embryo. Genes Dev $\underline{8}, 1897-1909$

Felcht M, Luck R, Schering A, Seidel P, Srivastava K, Hu J, Bartol A, Kienast Y, Vettel C, Loos EK (2012): Angiopoietin-2 differentially regulates angiogenesis through TIE2 and integrin signaling. J Clin Invest 122, 1991-2005 
Feng Y, vom Hagen F, Wang Y, Pfister F, Deutsch U, Hammes HP (2008): Angiopoietin-2-Defizienz reduziert die retinale Angiogenese durch verminderte MMP Aktivität. Diabetologie und Stoffwechsel 2008. 3-A136, Georg Thieme Verlag KG, Stuttgart 2008, 49

Fiedler U, Krissl T, Koidl S, Weiss C, Koblizek T, Deutsch U, Martiny-Baron G, Marme D, Augustin HG (2003): Angiopoietin-1 and angiopoietin-2 share the same binding domains in the Tie-2 receptor involving the first Ig-like loop and the epidermal growth factor-like repeats. J Biol Chem $\underline{278}, 1721-1727$

Fiedler U, Scharpfenecker M, Koidl S, Hegen A, Grunow V, Schmidt JM, Kriz W, Thurston G, Augustin HG (2004): The Tie-2 ligand angiopoietin-2 is stored in and rapidly released upon stimulation from endothelial cell Weibel-Palade bodies. Blood 103, 4150-4156

Fiedler U: Die Rolle des Angiopoietin-Tie-Systems in physiologischer und pathologischer Angiogenese. Cesar Symposium, Freiburg, 14. Juni - 16. Juni 2007

Gale NW, Yancopoulos GD (1999): Growth factors acting via endothelial cellspecific receptor tyrosine kinases: VEGFs, angiopoietins, and ephrins in vascular development. Genes Dev $\underline{13}, 1055-1066$

Gallagher DC, Bhatt RS, Parikh SM, Patel P, Seery V, McDermott DF, Atkins MB, Sukhatme VP (2007): Angiopoietin 2 is a potential mediator of high-dose interleukin 2-induced vascular leak. Clin Cancer Res $\underline{13}$, 2115-2120

Gill KA, Brindle NP (2005): Angiopoietin-2 stimulates migration of endothelial progenitors and their interaction with endothelium. Biochem Biophys Res Commun $\underline{36}$, 392-396

Goligorsky MS (2005): Endothelial cell dysfunction: can't live with it, how to live without it. Am J Physiol Renal Physiol 288, F871-880.

Grant MB, May WS, Caballero S, Brown GAJ, Guthrie SM, Mames RN, Byrne BJ, Vaught T, Spoerri PE, Peck AB (2002): Adult hematopoietic stem cells provide functional hemangioblast activity during retinal neovascularization. Nat Med $\underline{8}, 607-612$ 
Hansen TM, Singh H, Tahir TA, Brindle NP (2010): Effects of angiopoietins-1 and -2 on the receptor tyrosine kinase Tie2 are differentially regulated at the endothelial cell surface. Cell Signal $\underline{22}$, 527-532

Hegen A, Koidl S, Weindel K, Marme D, Augustin HG, Fiedler U (2004): Expression of angiopoietin-2 in endothelial cells is controlled by positive and negative regulatory promoter elements. Arterioscler Thromb Vasc Biol $\underline{24}, 1803-$ 1809

Horn F: Biochemie des Menschen - Das Lehrbuch für das Medizinstudium. 4. Auflage; Georg Thieme Verlag KG, Stuttgart 2009, 590

Iwama A, Hamaguchi I, Hashiyama M, Murayama Y, Yasunaga K, Suda T (1993): Molecular cloning and characterization of mouse TIE and TEK receptor tyrosine kinase genes and their expression in hematopoietic stem cells. Biochem Biophys Res Commun 195, 301-309

Khakoo AY, Finkel T (2005): Endothelial progenitor cells. Annu Rev Med 56, 79101

Kim K T, Choi HH, Steinmetz MO, Maco B, Kammerer RA, Ahn SY, Kim HZ, Lee GM, Koh GY (2005): Oligomerization and multimerization are critical for angiopoietin-1 to bind and phosphorylate Tie2. J Biol Chem 280, 20126-20131

Korhonen J, Polvi A, Partanen J, Alitalo K (1994): The mouse tie receptor tyrosine kinase gene: expression during embryonic angiogenesis. Oncogene $\underline{9}$, $395-403$

Kribben A, Herget-Rosenthal S, Pietruck F, Philipp T (2003): [Acute renal failure--an review]. Dtsch Med Wochenschr 128, 1231-1236

Kruse K (2009): Regulation der vaskulären Homöostase durch den Tie2 Liganden Angiopoietin-2 und Nitritoxid. URN: urn:nbn:de:bsz:25-opus-64337, URL: http://www.freidok.uni-freiburg.de/volltexte/6433/

Kuo MC, Patschan D, Patschan S, Cohen-Gould L, Park HC, Ni J, Addabbo F, Goligorsky MS (2008): Ischemia-Induced Exocytosis of Weibel-Palade Bodies Mobilizes Stem Cells. J Am Soc Nephrol 19, 2321-2330. 
Kümpers P, Hellpap J, David S, Horn R, Leitolf H, Haller H, Haubitz M (2009): Circulating angiopoietin-2 is a marker and potential mediator of endothelial cell detachment in ANCA-associated vasculitis with renal involvement. Nephrol Dial Transplant 24, 1845-1850

Kümpers P, Hafer C, David S, Hecker H, Lukasz A, Fliser D, Haller H, Kielstein JT, Faulhaber-Walter R (2010): Angiopoietin-2 in patients requiring renal replacement therapy in the ICU: relation to acute kidney injury, multiple organ dysfunction syndrome and outcome. Intensive Care Med $\underline{36}$, 462-470

Kurniati NF, van Meurs M, Vom Hagen F, Jongman RM, Moser J, Zwiers PJ, Struys MM, Westra J, Zijlstra JG, Hammes HP (2013): Pleiotropic effects of angiopoietin-2 deficiency do not protect mice against endotoxin-induced acute kidney injury. Nephrol Dial Transplant $\underline{28}$, 567-575

Lambiase PD, Edwards RJ, Anthopoulos P, Rahman S, Meng YG, Bucknall CA, Redwood SR, Pearson JD, Marber MS (2004): Circulating humoral factors and endothelial progenitor cells in patients with differing coronary collateral support. Circulation 109, 2986-2992

Leaf A (1973): Cell swelling. A factor in ischemic tissue injury. Circulation $\underline{48}$, $455-458$

Lekas M, Lekas P, Mei SH, Deng Y, Dumont DJ, Stewart DJ (2012): Tie2dependent neovascularization of the ischemic hindlimb is mediated by angiopoietin-2. PLoS One $\underline{7}$, e43568

Lemieux C, Maliba R, Favier J, Theoret JF, Merhi Y, Sirois MG (2005): Angiopoietins can directly activate endothelial cells and neutrophils to promote proinflammatory responses. Blood $\underline{105}, 1523-1530$

Lin Y, Weisdorf DJ, Solovey A, Hebbel RP (2000): Origins of circulating endothelial cells and endothelial outgrowth from blood. J Clin Invest 105, 71-77

Lorenzen J, Krämer R, Kliem V, Bode-Boeger SM, Veldink H, Haller H, Fliser D, Kielstein JT (2010): Circulating levels of osteopontin are closely related to glomerular filtration rate and cardiovascular risk markers in patients with chronic kidney disease. Eur J Clin Invest 40, 294-300. 
Lüllmann-Rauch R, Paulsen F: Taschenlehrbuch Histologie. 4. Auflage; Georg Thieme Verlag KG, Stuttgart 2012, 267-268

Maisonpierre PC, Suri C, Jones PF, Bartunkova S, Wiegand SJ, Radziejewski C, Compton D, McClain J, Aldrich TH, Papadopoulos N (1997): Angiopoietin-2, a natural antagonist for Tie2 that disrupts in vivo angiogenesis. Science $\underline{277}$, $55-60$

Meyne K: Handbuch Arterielle Verschlusskrankheit - Leitfaden zum Krankheitsbild. 1. Auflage; Schlütersche GmbH \& Co. KG Verlag und Druckerei, Hannover 2003, 15

Oh H, Takagi H, Suzuma K, Otani A, Matsumura M, Honda Y (1999): Hypoxia and vascular endothelial growth factor selectively up-regulate angiopoietin-2 in bovine microvascular endothelial cells. J Biol Chem $\underline{274}$, 15732-15739

Parikh SM, Mammoto T, Schultz A, Yuan HT, Christiani D, Karumanchi SA, Sukhatme VP (2006): Excess circulating angiopoietin-2 may contribute to pulmonary vascular leak in sepsis in humans. PLoS Med $\underline{3}$, e46

Partanen J, Armstrong E, Makela TP, Korhonen J, Sandberg M, Renkonen R, Knuutila S, Huebner K, Alitalo K (1992): A novel endothelial cell surface receptor tyrosine kinase with extracellular epidermal growth factor homology domains. Mol Cell Biol $\underline{12}, 1698-1707$

Patschan D, Krupincza K, Patschan S, Zhang Z, Hamby C, Goligorsky MS (2006a): Dynamics of mobilization and homing of endothelial progenitor cells after acute renal ischemia: modulation by ischemic preconditioning. Am $\mathrm{J}$ Physiol Renal Physiol 291, F176-185

Patschan D, Plotkin M, Goligorsky MS (2006b): Therapeutic use of stem and endothelial progenitor cells in acute renal injury: ça ira. Curr Opin Pharmacol $\underline{6}$, 176-183

Patschan D, Patschan S, Gobe GG, Chintala S, Goligorsky MS (2007): Uric acid heralds ischemic tissue injury to mobilize endothelial progenitor cells. J Am Soc Nephrol $\underline{18}, 1516-1524$ 
Patschan D, Patschan S, Wessels JT, Becker JU, David S, Henze E, Goligorsky MS, Müller GA (2010): Epac-1 activator 8-O-cAMP augments renoprotective effects of syngeneic [corrected] murine EPCs in acute ischemic kidney injury. Am J Physiol Renal Physiol 298, F78-85

Patschan D, Hildebrandt A, Rinneburger J, Wessels JT, Patschan SA, Becker JU, Henze E, Kruger A, Muller GA (2012): The hormone Melatonin stimulates renoprotective effects of early outgrowth endothelial progenitor cells in acute ischemic kidney injury. Am J Physiol Renal Physiol 302, F1305-1312

Rafii S, Lyden D (2003): Therapeutic stem and progenitor cell transplantation for organ vascularization and regeneration. Nat Med $\underline{9}, 702-712$

Rehman J, Li J, Orschell CM, March KL (2003): Peripheral blood "endothelial progenitor cells" are derived from monocyte/macrophages and secrete angiogenic growth factors. Circulation 107, 1164-1169

Rehner G, Daniel H: Biochemie der Ernährung. 3. Auflage; Spektrum Akademsicher Verlag, Heidelberg 2010, 569

Rifai K, Bode-Boeger SM, Martens-Lobenhoffer J, Ernst T, Kretschmer U, Hafer C, Fliser D, Manns MP, Kielstein JT (2010): Removal of asymmetric dimethylarginine during artificial liver support using fractionated plasma separation and adsorption. Scand J Gastroenterol 45, 1110-1115

Rookmaaker MB, Smits AM, Tolboom H, Van't Wout K, Martens AC, Goldschmeding R, Joles JA, Van Zonneveld AJ, Gröne H-J, Rabelink TJ (2003): Bone-marrow-derived cells contribute to glomerular endothelial repair in experimental glomerulonephritis. Am J Pathol 163, 553-562

Roviezzo F, Tsigkos S, Kotanidou A, Bucci M, Brancaleone V, Cirino G, Papapetropoulos A (2005): Angiopoietin-2 causes inflammation in vivo by promoting vascular leakage. J Pharmacol Exp Ther $\underline{314}$, 738-744

Saharinen P, Kerkela K, Ekman N, Marron M, Brindle N, Lee GM, Augustin H, Koh GY, Alitalo K (2005): Multiple angiopoietin recombinant proteins activate the Tie1 receptor tyrosine kinase and promote its interaction with Tie2. J Cell Biol 169, 239-243 
Sato TN, Qin Y, Kozak CA, Audus KL (1993): Tie-1 and tie-2 define another class of putative receptor tyrosine kinase genes expressed in early embryonic vascular system [published erratum appears in Proc Natl Acad Sci U S A 1993 Dec 15; 90(24):12056]. Proc Natl Acad Sci U S A 90, 9355-9358

Sato TN, Tozawa Y, Deutsch U, Wolburg Buchholz K, Fujiwara Y, Gendron Maguire M, Gridley T, Wolburg H, Risau W, Qin Y (1995): Distinct roles of the receptor tyrosine kinases Tie-1 and Tie-2 in blood vessel formation. Nature $\underline{376}$, 70-74

Schnürch H, Risau W (1993): Expression of tie-2, a member of a novel family of receptor tyrosine kinases, in the endothelial cell lineage. Development $\underline{119}$, 957-968

Schuster MD, Kocher AA, Seki T, Martens TP, Xiang G, Homma S, Itescu S (2004): Myocardial neovascularization by bone marrow angioblasts results in cardiomyocyte regeneration. Am J Physiol Heart Circ Physiol 287, H525-532

Siegenthaler W, Blum HE: Klinische Pathophysiologie. 9. Auflage; Georg Thieme Verlag KG, Stuttgart 2006, 957

Stratmann A, Risau W, Plate KH (1998): Cell type-specific expression of angiopoietin-1 and angiopoietin-2 suggests a role in glioblastoma angiogenesis. Am J Pathol $\underline{153}, 1459-1466$

Sugimachi K, Tanaka S, Taguchi K, Aishima S, Shimada M, Tsuneyoshi M (2003): Angiopoietin switching regulates angiogenesis and progression of human hepatocellular carcinoma. J Clin Pathol $\underline{56}$, 854-860

Udani V, Santarelli J, Yung Y, Cheshier S, Andrews A, Kasad Z, Tse V (2005): Differential expression of angiopoietin-1 and angiopoietin-2 may enhance recruitment of bone-marrow-derived endothelial precursor cells into brain tumors. Neurol Res $\underline{27}, 801-806$

Urbich C, Dimmeler S (2004a): Endothelial progenitor cells functional characterization. Trends Cardiovasc Med 14, 318-322

Urbich C, Dimmeler S (2004b): Endothelial progenitor cells: characterization and role in vascular biology. Circ Res $\underline{95}, 343-353$ 
Wakui S, Yokoo K, Muto T, Suzuki Y, Takahashi H, Furusato M, Hano H, Endou $\mathrm{H}$, Kanai $Y$ (2006): Localization of Ang-1, -2, Tie-2, and VEGF expression at endothelial-pericyte interdigitation in rat angiogenesis. Lab Invest $\underline{86}, 1172$ 1184

Yamamoto T, Tada T, Brodsky SV, Tanaka H, Noiri E, Kajiya F, Goligorsky MS (2002): Intravital videomicroscopy of peritubular capillaries in renal ischemia. Am J Physiol Renal Physiol 282, F1150-1155

Yoder MC, Mead LE, Prater D, Krier TR, Mroueh KN, Li F, Krasich R, Temm CJ, Prchal JT, Ingram DA (2007): Redefining endothelial progenitor cells via clonal analysis and hematopoietic stem/progenitor cell principals. Blood $\underline{109}$, 1801-1809

Yuan HT, Khankin EV, Karumanchi SA, Parikh SM (2009): Angiopoietin 2 is a partial agonist/antagonist of Tie2 signaling in the endothelium. Mol Cell Biol $\underline{29}$, 2011-2022 


\section{Danksagung}

Ich bedanke mich herzlich bei meinem Doktorvater PD Dr. med Daniel Patschan, Oberarzt der Abteilung Nephrologie und Rheumatologie des Universitätsklinikums Göttingen, für die Vergabe dieses spannenden Themas und für die stets großartige Betreuung während der gesamten Dauer.

Ein großer Dank gilt auch dem gesamten Laborteam um Frau Elvira Henze für die allzeit nette und intensive Betreuung während der zahlreichen Laborarbeiten. Das gesamte Team stand einem stets hilfreich zur Seite.

Weiterhin bedanke ich mich bei Frau Annika Krüger für die Unterstützung bei der Isolierung und Kultivierung der Zellen und deren Färbung.

Ich danke den Mitarbeitern des Tierstalls für die gewissenhafte Betreuung und Pflege der Mäuse.

Nicht zu vergessen sind meine Mit-Doktoranden Jörg Rinneburger und Nazif Idrizi, bei denen ich mich für die nette und konstruktive Zusammenarbeit während der gesamten Zeit ebenfalls recht herzlich bedanke. 